\title{
Provas matemáticas no ensino médio: um estudo de caso.
}

Ednaldo José Leandro 
Assinatura:

\section{Provas matemáticas no ensino médio: um estudo de caso.}

Dissertação apresentada ao Instituto de Ciências Matemáticas e de Computação - ICMC-USP, como parte dos requisitos para obtenção do título de Mestre em Ciências - Programa de Mestrado Profissional em Matemática. VERSÃO REVISADA.

Área de concentração: Matemática

Orientadora: Profa. Dra. Karla Roberta Pereira Sampaio Lima 
AUTORIZO A REPRODUÇÃO E DIVULGAÇÃO TOTAL OU PARCIAL DESTE TRABALHO, POR QUALQUER MEIO CONVENCIONAL OU ELETRÔNICO, PARA FINS DE ESTUDO E PESQUISA, DESDE QUE CITADA A FONTE.

Ficha catalográfica elaborada pela Biblioteca Prof. Achille Bassi

e Seção Técnica de Informática, ICMC/USP, com os dados fornecidos pelo(a) autor(a)

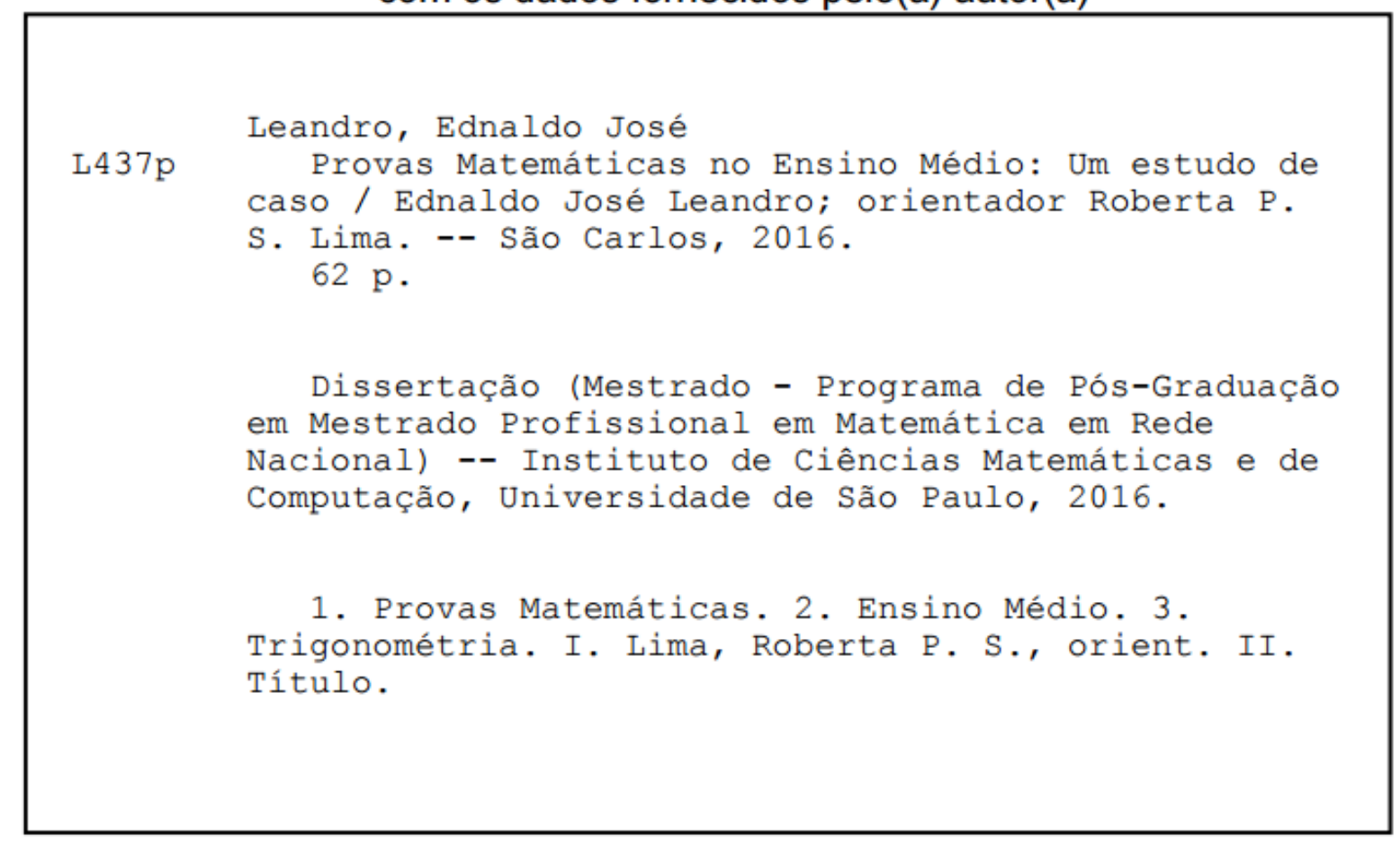


Ednaldo José Leandro

\section{Mathematics proofs in high school: a case study.}

Master dissertation submitted to the Instituto de Ciências Matemáticas e de Computação - ICMCUSP, in partial fulfillment of the requirements for the degree of Mathematics Professional Master's Program. FINAL VERSION.

Concentration Area: Mathematics

Advisor: Profa. Dra. Karla Roberta Pereira Sampaio Lima

\section{USP - São Carlos}

July 2016 


\section{DEDICATÓRIA}

Aos meus filhos, Eduardo Augusto, Maria Eduarda e Marco Antônio e as minhas netas, Helena, Isabelle e Giovana, por me completarem plenamente.

À minha família, por todo o apoio. 


\section{AGRADECIMENTOS}

A Professora Doutora Karla Roberta P. S. Lima, pela disposição e orientação que fez com que este trabalho fosse produzido da melhor maneira possível.

À Sociedade Brasileira de Matemática por acreditar na formação de professores através do PROFMAT.

Aos Professores Doutores do programa PROFMAT da USP-LESTE, pelos ensinamentos.

A todos os colegas do Programa, por tornarem o curso prazeroso. Grato pela amizade de todos.

À minha amiga e companheira, Márcia Elisa Viviani, por todo apoio e paciência. 
"Um bom ensino da Matemática forma melhores hábitos de pensamento e habilita o indivíduo a usar melhor a sua inteligência." (Irene de Albuquerque) 


\section{RESUMO}

Por meio de acompanhamento realizado junto a quatro professores da rede estadual de ensino de São Paulo, realizamos um estudo de caso, com foco na abordagem das provas matemáticas no Ensino Médio. O texto descreve o acompanhamento das aulas, motivações e os obstáculos existentes para o desenvolvimento do tema em sala de aula. Para o desenvolvimento da pesquisa, utilizamos como referencial teórico, os seguintes trabalhos: Thompson (1992), sobre concepções docentes; as tipologias e funções das provas matemáticas, de Balacheff e De Villiers, respectivamente. Foram utilizados os seguintes instrumentos para a coleta de dados: observação direta, anotações de campo e entrevistas. Os resultados obtidos apontam para uma prática pedagógica utilitarista sem a participação ativa dos alunos. Quanto às provas matemáticas, constatamos a sua abordagem de forma intencional e planejada, sendo abordadas, no entanto, apenas em turmas específicas e ligadas ao interesse pessoal do professor e ainda, em geral, sem a participação ativa dos alunos no processo. Acreditamos não ser este o ambiente ideal para o desenvolvimento das provas matemáticas em sala de aula, que deveria ocorrer num espaço voltado à argumentação, levantamento de hipóteses, elaboração de conjecturas de modo a permitir o avanço dos alunos nos níveis das provas elaboradas. Constatamos ainda a influência de fatores como: interesse das turmas, indisciplina, cobranças internas (organização da sala, comportamento dos alunos em sala, abordagem dos conteúdos previstos) e externas (desempenho satisfatório nas avaliações internas e externas das quais a escola participa).

Palavras-chave: Provas Matemáticas, Ensino Médio e Trigonometria. 


\begin{abstract}
Through monitoring carried out with four teachers of the state of São Paulo teaching, we conducted a case study with a focus on addressing the mathematical proofs in high school. The text describes the monitoring of classes, existing motivations and obstacles to the issue of development in the classroom. For the development of research, we used as a theoretical reference, the following work: Thompson (1992) on teachers conceptions; the types and functions of mathematical proofs of Balacheff and De Villiers, respectively. The instruments for data collection were used: direct observation, field notes and interviews. The results point to a utilitarian pedagogical practice without the active participation of students. As for mathematical proofs, found his approach intentionally and planned, being addressed, however, only in specific classes and linked to the staff of teacher interest and also, in general, without the active participation of students in the process. We believe this is not the ideal environment for the development of mathematical proofs in the classroom, which should occur in an area facing the argument, raise hypotheses, conjectures preparing to allow the advancement of students in levels of elaborate tests. Still found the influence of factors such as interest groups, lack of discipline, internal charges (room organization, students' behavior in class, approach the expected content) and external (satisfactory performance in internal and external ratings of which the school participates).
\end{abstract}

Keywords: Mathematical Proofs, high school and Trigonometry. 


\section{SUMÁRIO}

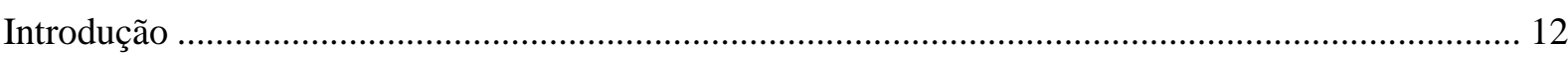

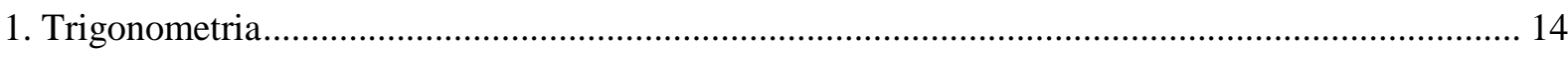

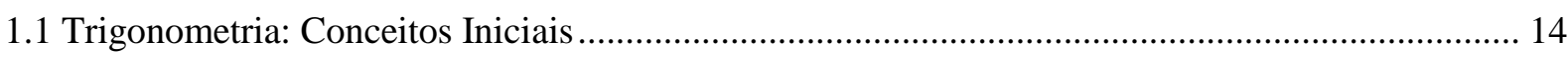

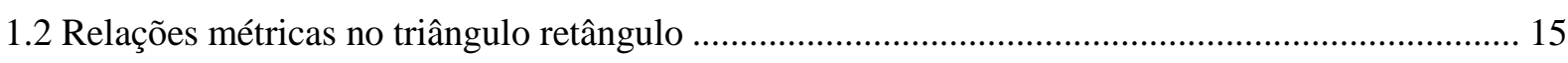

1.3 Razões trigonométricas em um triângulo retângulo................................................................ 17

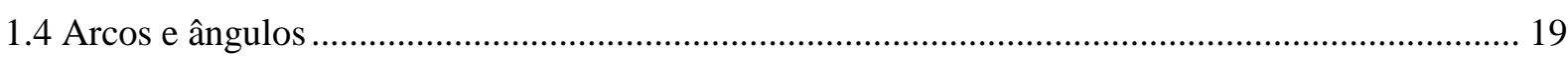

1.5 Propriedade dos ângulos complementares e Fundamental ......................................................... 20

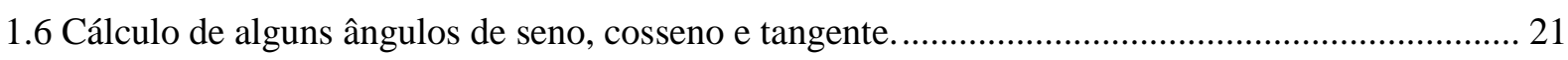

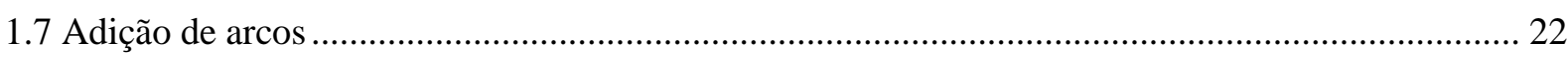

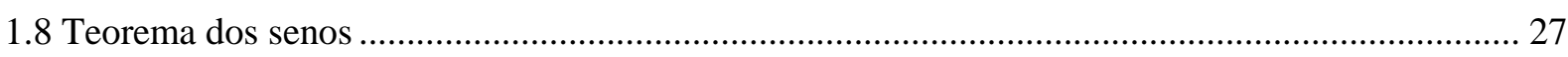

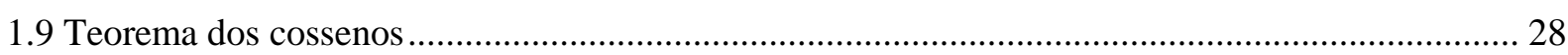

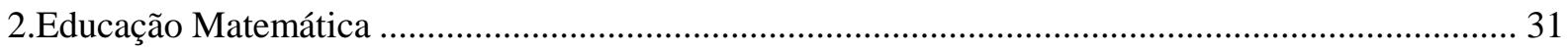

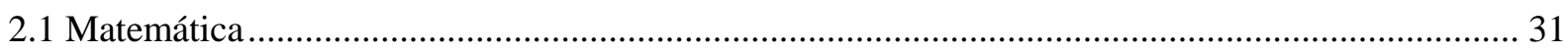

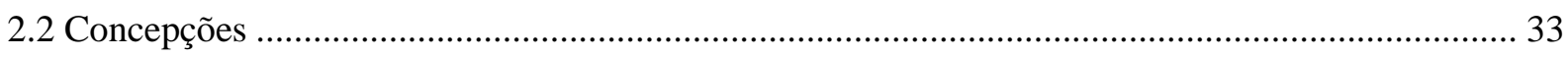

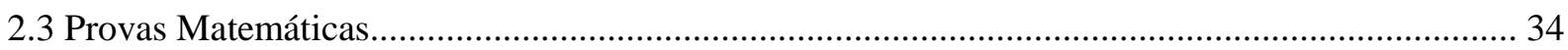

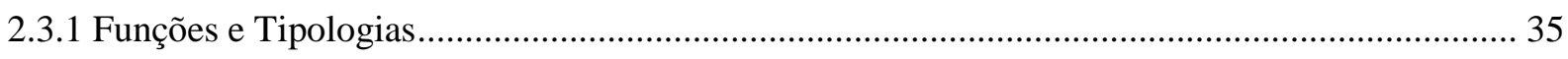

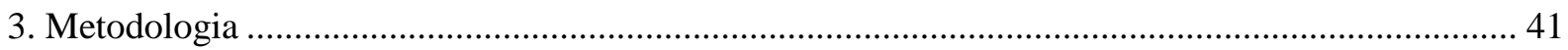

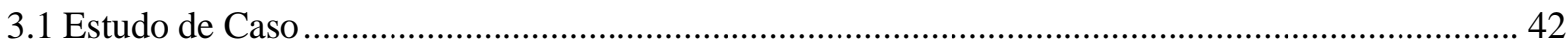

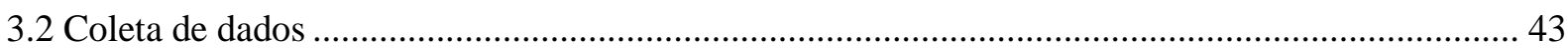

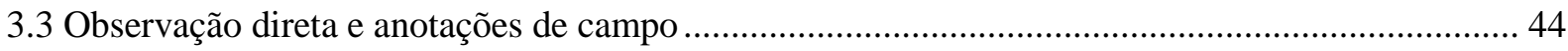

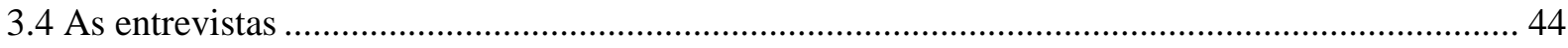

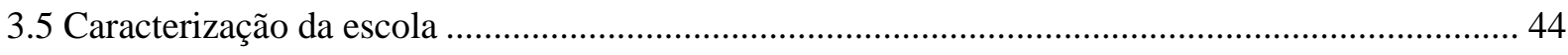

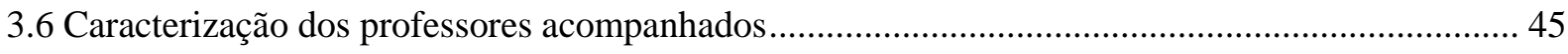

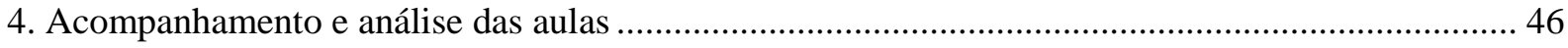

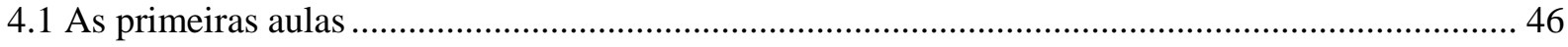

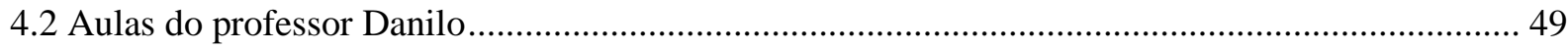

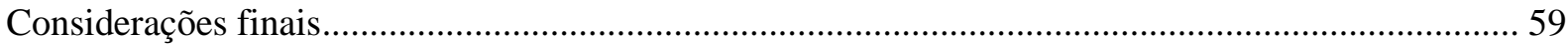

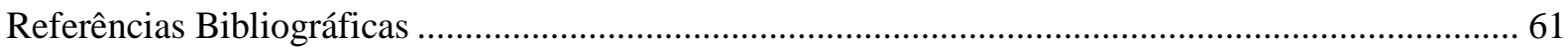


FIGURAS

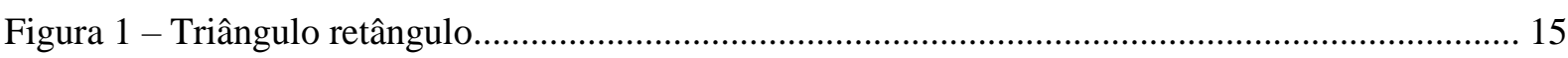

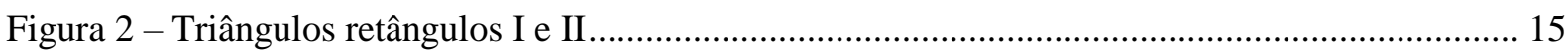

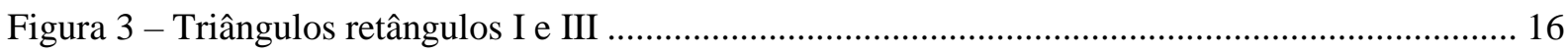

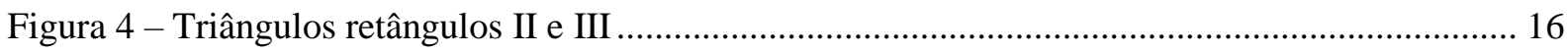

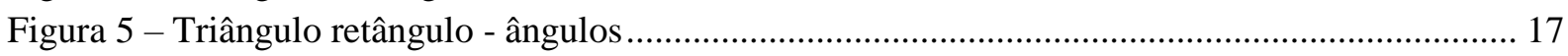

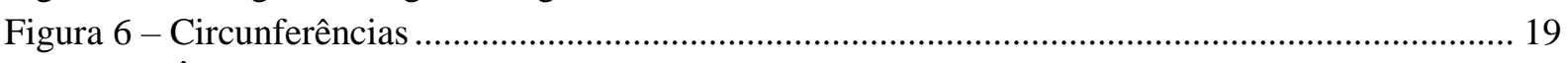

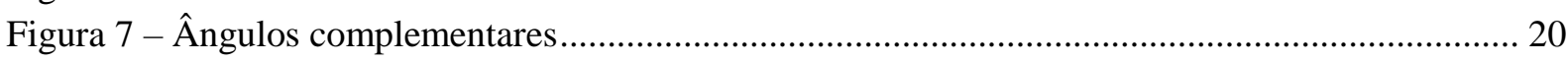

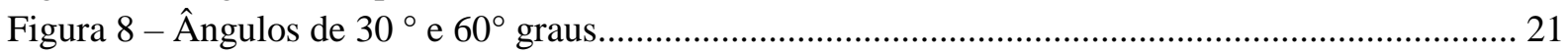

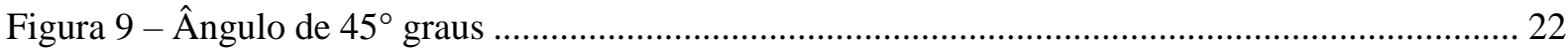

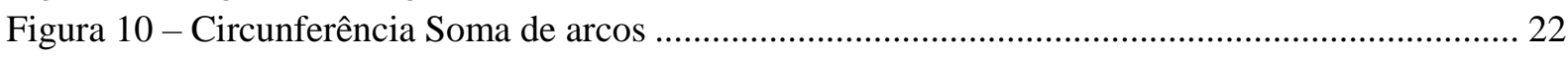

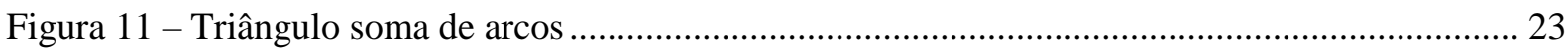

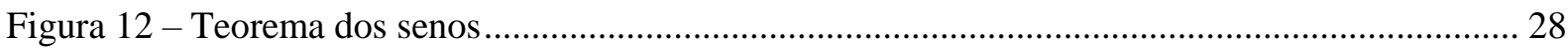

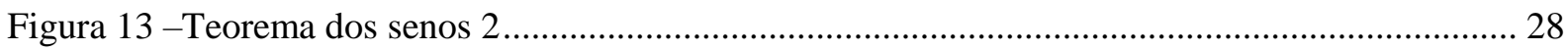

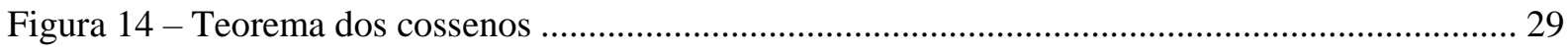

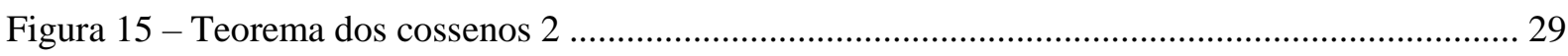

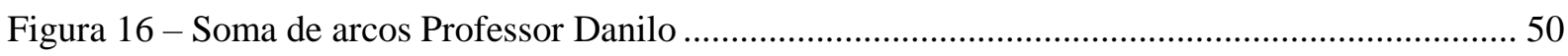

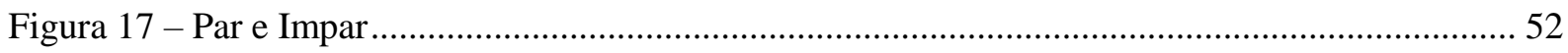

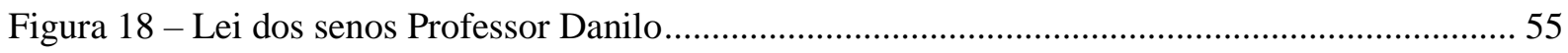

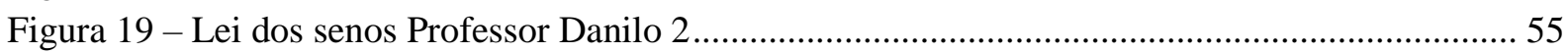

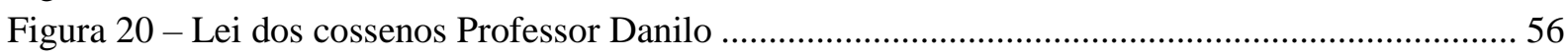

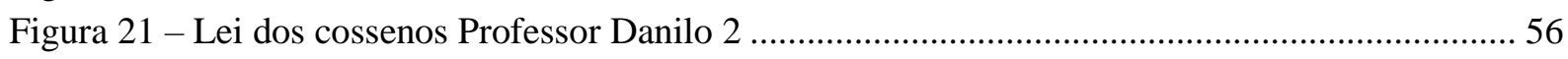




\section{Introdução}

As provas matemáticas na educação básica tem sido foco de várias pesquisas na Educação Matemática. O programa PROFMAT - (Programa de Mestrado Profissional em Matemática em Rede Nacional) tem como foco principal os professores de matemática do ensino básico das escolas públicas e busca o aprofundamento do conteúdo matemático relevante para sua atuação docente, com o fim específico de melhorar o ensino aprendizagem.

O Trabalho de Conclusão de Curso (TCC) deve versar, portanto, sobre temas específicos pertinentes ao currículo de matemática do ensino básico e que tenham impacto na prática didática em sala de aula.

Percebemos, ao longo das disciplinas do curso, uma abordagem sistemática das provas matemáticas nos materiais utilizados, além de participarmos da elaboração de um grande levantamento das provas matemáticas elaboradas pelos alunos do ensino fundamental no nosso primeiro mestrado (Leandro, 2006). Surgem as perguntas geradoras deste trabalho: os professores do ensino médio privilegiam as provas matemáticas em suas aulas? Se sim, de que forma o fazem? Que tipologias de provas buscam desenvolver em sala de aula ou elaboram?

Assim, resolvemos propor ao Programa de Pós-Graduação a elaboração de uma pesquisa com o objetivo de responder a essas perguntas.

Sabendo que existe uma distância entre o discurso e a ação efetivamente realizada, resolvemos acompanhar diretamente na sala de aula quatro professores do ensino médio de uma escola da rede estadual e elaborar um estudo de caso.

Para encontrar respostas para tais questões, estabelecemos um planejamento a ser seguido para alcançamos nossos objetivos.

\section{Objetivo Geral}

- Elaborar um estudo de caso para responder a questão: Os professores do ensino médio privilegiam as provas matemáticas em suas aulas? Se sim, de que forma o fazem? Que tipologias de provas buscam desenvolver em sala de aula ou elaboram? Para responder a essas perguntas acompanhamos as aulas de quatro professores desse nível de ensino de uma escola pública da rede pública do Estado de São Paulo. 


\section{Objetivos Específicos:}

- Acompanhar situações de aprendizagem de estudantes do ensino médio, com foco nas provas matemáticas elaboradas;

- Avaliar que tipologias de provas matemáticas os professores abordam e incentivam em suas práticas de ensino em sala de aula.

Definido nosso objetivo de pesquisa e o caminho percorrido para a elaboração da questão de pesquisa, continuamos a elaborar o corpo do trabalho.

Assim, no primeiro capítulo, abordamos tópicos de trigonometria, pois foi principalmente durante o acompanhamento dessa temática que presenciamos as provas matemáticas sendo exploradas em sala de aula.

No segundo capítulo, apresentamos o referencial teórico utilizado durante as análises desta pesquisa: perspectivas de ensino com maior frequência nas práticas dos professores; tipologias e as funções atribuídas às provas matemáticas. A discussão teórica nos revelaram pistas e permitiram reflexões para alcançar os objetivos propostos.

No terceiro capítulo, apresentamos a metodologia adotada para o acompanhamento e análise dos dados. Como buscamos compreender, explorar acontecimentos e contextos complexos, escolhemos o estudo de caso, indicado para essas situações. Esse procedimento nos orientou na coleta de dados.

Reservamos o último capítulo para apresentar uma descrição e análise dos acompanhamentos realizados para a coleta de dados. Os acompanhamentos foram realizados em sala de aula, durante os horários normais de aulas de uma escola da rede estadual de São Paulo. Ao todo, acompanhamos quatro professores licenciados em matemática, identificados como: Alberto, Beatriz, Carlos e Danilo. 


\section{Capítulo 1}

\section{Trigonometria}

Neste capítulo, apresentamos alguns conteúdos que são a base para o estudo trigonométrico, a saber: ângulo, triângulo retângulo, semelhança de triângulos, relações trigonométricas no triângulo retângulo, definições e algumas identidades.

A ordem didática seguida a seguir é a mesma apresentada nas aulas acompanhadas no ensino médio.

\subsection{Trigonometria: Conceitos Iniciais}

O Prob. 56 do Papiro de Rhind tem especial interesse por conter rudimentos de trigonometria e uma teoria de triângulos semelhantes. $\mathrm{Na}$ construção de pirâmides era essencial manter uma inclinação constante das faces e pode ter sido essa preocupação a levar os egípcios a introduzir um conceito equivalente ao de cotangente de um ângulo. Na tecnologia moderna é usual medir o grau de inclinação de uma reta por uma razão entre segmentos verticais e horizontais que é recíproca da usada no Egito (BOYER, 2010, p.13).

O Papiro Rhind, rico em informações matemáticas, contém uma série de tabelas e problemas resolvidos. As soluções elaboradas revelam que os egípcios já possuíam conhecimentos sobre as razões trigonométricas num triângulo retângulo e a teoria sobre a semelhança entre triângulos, conhecimentos estes utilizados na construção das pirâmides.

Os livros de história da matemática ainda indicam que a trigonometria surgiu com o intuito de calcular distâncias com base na medida de ângulos, apontando como seu maior estudioso o astrônomo grego Hiparco de Nicéia (190-125 a.C.), que relacionou os lados e os ângulos de um triângulo.

Os estudos em Astronomia deram grande impulso ao desenvolvimento da trigonometria, pois foi a partir dos trabalhos de grandes astrônomos, como o próprio Hiparco, que surgiram os seus primeiros fundamentos.

A abordagem da trigonometria na educação básica tem sua importância e encontra-se prevista nos currículos escolares da educação básica, não se limitando apenas aos estudos dos 
triângulos. Sabemos que a trigonometria tem aplicações em diversas áreas das ciências exatas, sendo fundamental, por exemplo, no estudo da Análise, Mecânica, Acústica, engenharias, etc.

\subsection{Relações métricas no triângulo retângulo}

Dado o triângulo retângulo $\mathrm{ABC}$, reto em $\mathrm{A}$, ao traçarmos a altura relativa ao vértice A, obtemos três triângulos semelhantes.

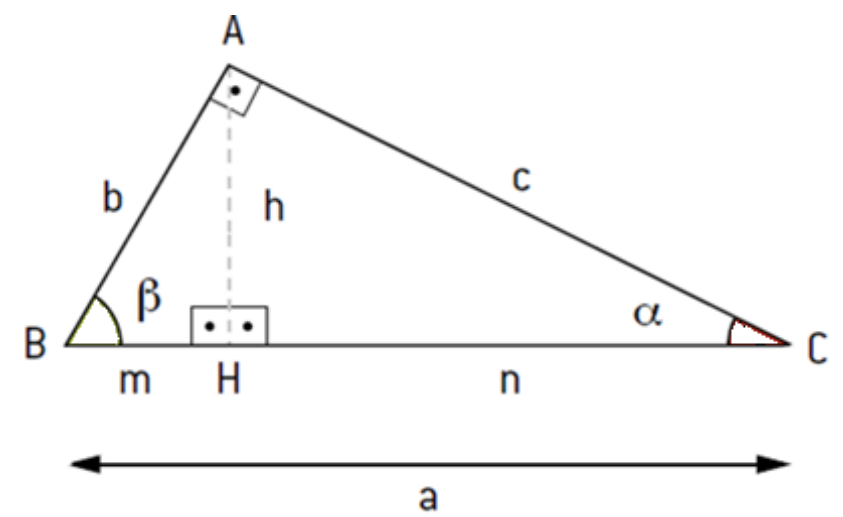

Figura 1 - Triângulo retângulo

Fonte: Autoria própria

onde:

a - medida da hipotenusa do triângulo $\mathrm{ABC}$

$\mathrm{b}$ - medida de um cateto do triângulo $\mathrm{ABC}$

$\mathrm{c}$ - medida de um cateto do triângulo $\mathrm{ABC}$

$\mathrm{m}$ - projeção ortogonal do cateto $\mathrm{AB}$ sobre a hipotenusa $\mathrm{BC}$

$\mathrm{n}$ - projeção ortogonal do cateto $\mathrm{AC}$ sobre a hipotenusa $\mathrm{BC}$

$\mathrm{h}$ - medida da altura do triângulo $\mathrm{ABC}$ relativa à hipotenusa $\mathrm{BC}$.

É através da semelhança que são deduzidas as relações métricas. Vejamos:

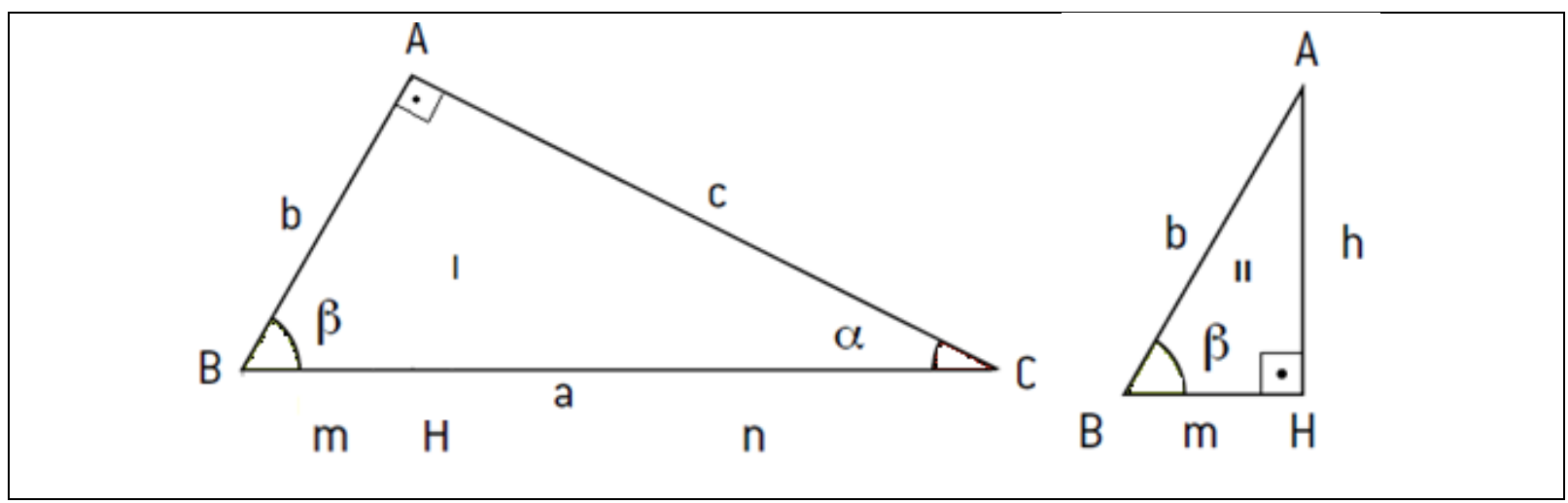

Figura 2 - Triângulos retângulos I e II 
Dos triângulos I e II, semelhantes pelo caso ângulo-ângulo, temos que:

$$
\begin{aligned}
& \frac{b}{m}=\frac{a}{b} \rightarrow b^{2}=a \cdot m \\
& \frac{c}{h}=\frac{a}{b} \rightarrow a \cdot h=b \cdot c
\end{aligned}
$$

Da semelhança dos triângulos I e III:

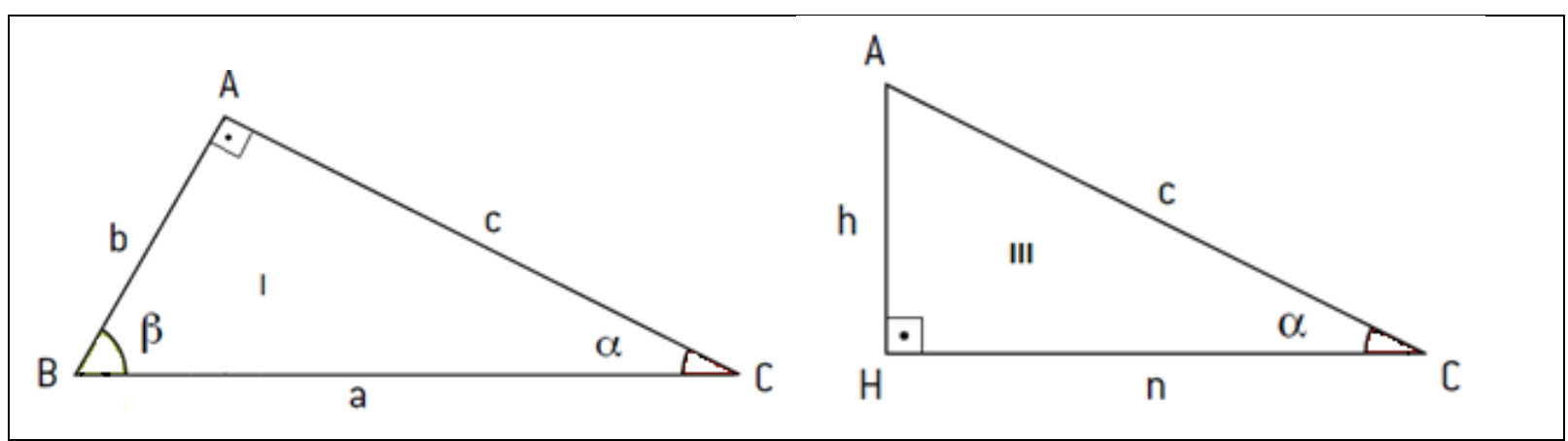

Figura 3 Triângulos retângulos I e III Fonte: Autoria própria

Encontramos:

$\frac{c}{n}=\frac{a}{c} \rightarrow c^{2}=a . n$

E da semelhança dos triângulos II e III:

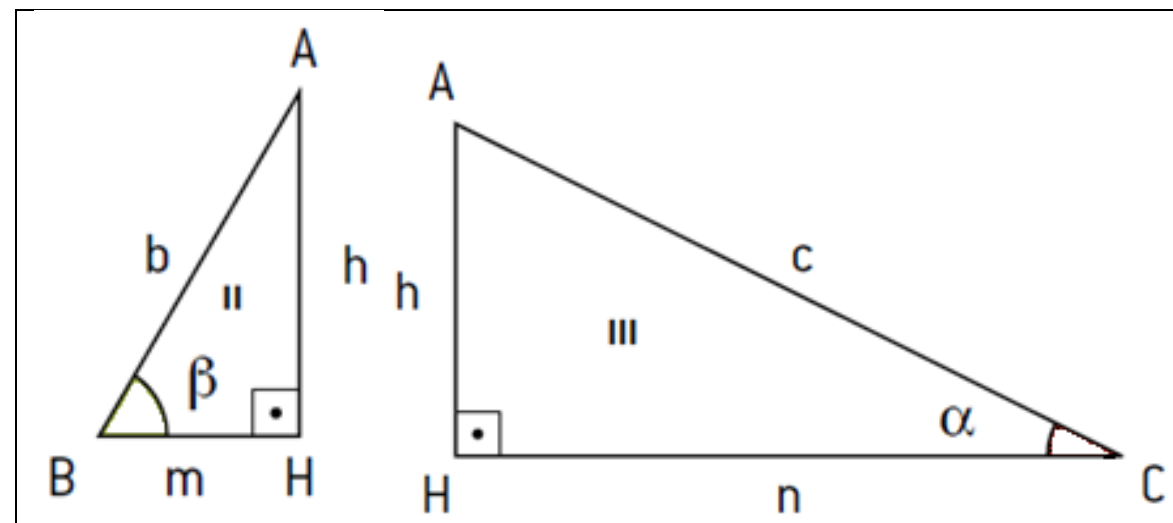

Figura 4 - Triângulos retângulos II e III Fonte: Autoria própria 


$$
\frac{h}{n}=\frac{m}{h} \rightarrow h^{2}=n \cdot m
$$

De (i) e (iii) podemos concluir que:

$$
\frac{\left\{\begin{array}{l}
b^{2}=a \cdot m \text { (i) } \\
c^{2}=a \cdot n \text { (iii) }
\end{array}\right.}{b^{2}+c^{2}=a \cdot m+a \cdot n}
$$

E como $: b^{2}+c^{2}=a \cdot m+a \cdot n=a \cdot(m+n)=a \cdot a=a^{2}$, obtemos :

$$
a^{2}=b^{2}+c^{2}
$$

\subsection{Razões trigonométricas em um triângulo retângulo}

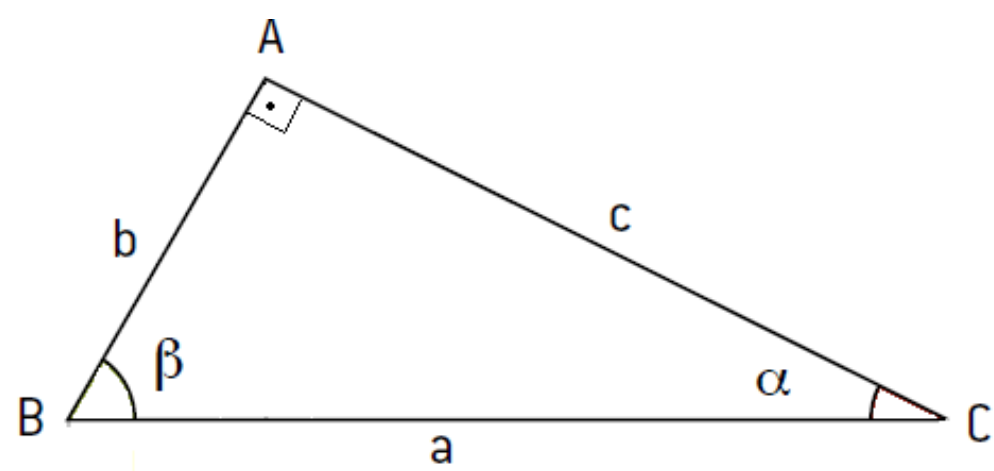

Figura 5 - Triângulo retângulo - ângulos Fonte: Autoria própria

Dado um triângulo retângulo, definimos como seno, cosseno e tangente de um ângulo agudo as relações a seguir:

a) Com relação ao ângulo agudo $\alpha$ :

$$
\begin{aligned}
& \text { sen } \alpha=\frac{\text { cateto oposto } \mathrm{a} \alpha}{\text { hipotenusa }}=\frac{\mathrm{b}}{\mathrm{a}} \\
& \cos \alpha=\frac{\text { cateto adjacente } \mathrm{a} \alpha}{\text { hipotenusa }}=\frac{\mathrm{c}}{\mathrm{a}} \\
& \operatorname{tg} \alpha=\frac{\operatorname{sen} \alpha}{\cos \alpha}=\frac{\text { cateto oposto }}{\text { cateto adjacente }}=\frac{\mathrm{b}}{\mathrm{c}}
\end{aligned}
$$


b) Com relação ao ângulo agudo $\beta$ :

sen $\beta=\frac{\text { cateto oposto a } \beta}{\text { hipotenusa }}=\frac{\mathrm{c}}{\mathrm{a}}$

$\cos \beta=\frac{\text { cateto adjacente } \mathrm{a} \beta}{\text { hipotenusa }}=\frac{\mathrm{b}}{\mathrm{a}}$

$\operatorname{tg} \beta=\frac{\operatorname{sen} \beta}{\cos \beta}=\frac{\text { cateto oposto }}{\text { cateto adjacente }}=\frac{\mathrm{c}}{\mathrm{b}}$

As razões anteriores quando invertidas são denominadas: cossecante, secante e cotangente, respectivamente. Ou seja:

a) Com relação ao ângulo agudo $\alpha$ :

$\cos \sec \alpha=\frac{1}{\operatorname{sen} \alpha}=\frac{\mathrm{a}}{\mathrm{b}}$

$\sec \alpha=\frac{1}{\cos \alpha}=\frac{\mathrm{a}}{\mathrm{c}}$

$\operatorname{cotg} \alpha=\frac{1}{\operatorname{tg} \alpha}=\frac{\mathrm{c}}{\mathrm{b}}$

b) Com relação ao ângulo agudo $\beta$ :

$\cos \sec \beta=\frac{1}{\operatorname{sen} \beta}=\frac{\mathrm{c}}{\mathrm{b}}$

$\sec \beta=\frac{1}{\cos \beta}=\frac{\mathrm{b}}{\mathrm{c}}$

$\operatorname{cotg} \beta=\frac{1}{\operatorname{tg} \beta}=\frac{\mathrm{b}}{\mathrm{c}}$ 


\subsection{Arcos e ângulos}

Definimos como arco de uma circunferência cada uma das partes em que ela é dividida por dois de seus pontos.

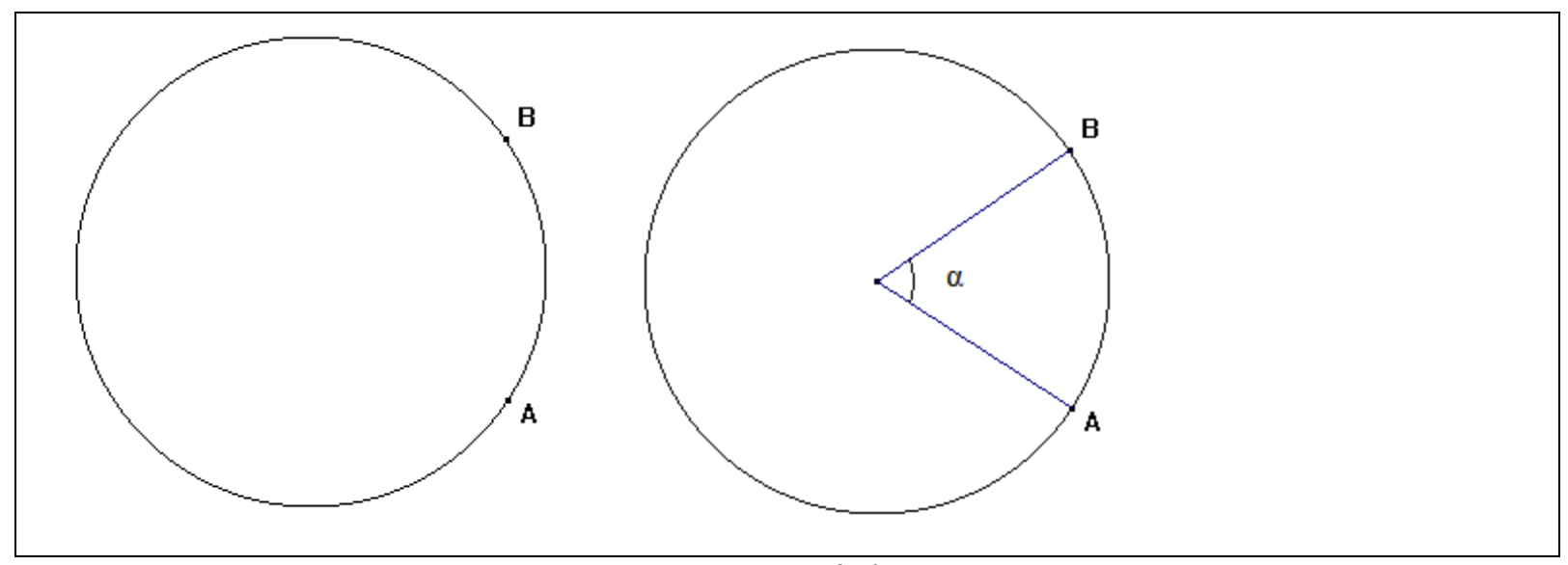

Figura 6 - Circunferências

Fonte: Autoria própria

Dizemos que a medida do um arco é igual à medida do ângulo central que o determina, ou seja:

$$
m(A B)=\alpha
$$

\section{$\underline{\text { Graus }}$}

Considerando o arco $\mathrm{AB}$ da figura anterior, contido numa circunferência de raio $\mathrm{r}$ de centro $\mathrm{O}$, tal que o comprimento do arco AB é igual a $\frac{1}{360}$ do comprimento de C. Define-se a medida do ângulo AOB como sendo 1 grau $\left(1^{\circ}\right)$ e a medida do arco $\mathrm{AB}$ como sendo 1 grau $\left(1^{\circ}\right)$, ou seja:

$$
m(A \widehat{O} B)=m(A B)=1^{\circ}
$$

\section{$\underline{\text { Radiano }}$}

Considerando ainda o arco $\mathrm{AB}$, contido numa circunferência de raio $r$, tal que o comprimento do arco $\mathrm{AB}$ seja igual a r. Neste caso, dizemos que a medida do ângulo $m(A \widehat{O B})$ e do arco $\mathrm{AB}$ é 1 radiano ( $1 \mathrm{rad})$. 


\subsection{Propriedade dos ângulos complementares e Fundamental}

A relação entre o seno, cosseno e a tangente de um ângulo agudo e dos ângulos complementares recebem destaque na maioria dos livros didáticos.

Ângulos complementares:

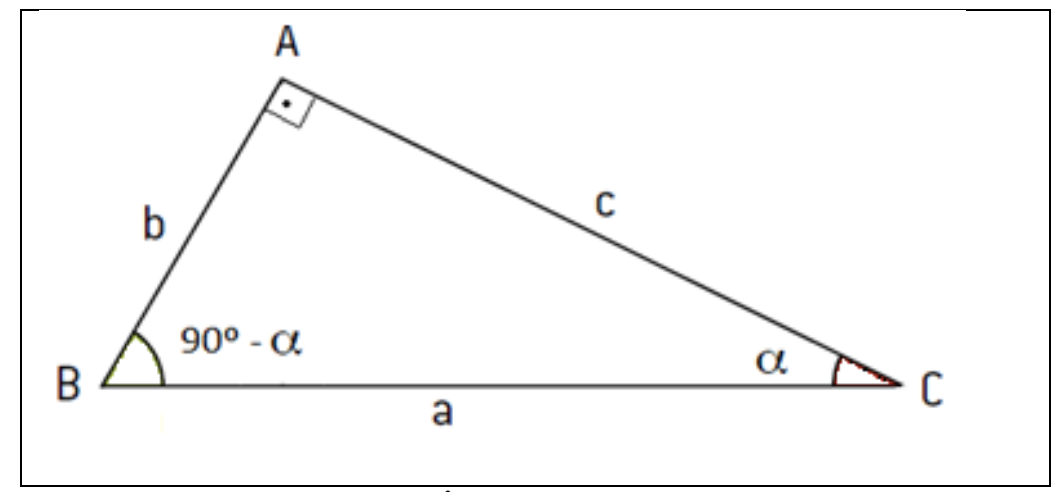

Figura 7 - Ângulos complementares

Fonte: Autoria própria

$$
\left.\begin{array}{l}
\left.\begin{array}{c}
\operatorname{sen} \alpha=\frac{\mathrm{b}}{\mathrm{a}} \\
\cos \left(90^{\circ}-\alpha\right)=\frac{\mathrm{b}}{\mathrm{a}}
\end{array}\right\} \Rightarrow \operatorname{sen} \alpha=\cos \left(90^{\circ}-\alpha\right) \\
\cos \alpha=\frac{\mathrm{c}}{\mathrm{a}} \\
\operatorname{sen}\left(90^{\circ}-\alpha\right)=\frac{\mathrm{c}}{\mathrm{a}}
\end{array}\right\} \Rightarrow \cos \alpha=\operatorname{sen}\left(90^{\circ}-\alpha\right)
$$

Aplicando o teorema de Pitágoras no triângulo ABC, deduzimos uma identidade importante, que permite obter uma razão trigonométrica para um ângulo, a partir de outra razão conhecida.

$$
\begin{gathered}
b^{2}+c^{2}=a^{2}, \quad \text { dividindo } \quad \text { os } \quad \text { membros por } a^{2}, \quad \text { teremos: } \\
\frac{b^{2}}{a^{2}}+\frac{c^{2}}{a^{2}}=\frac{a^{2}}{a^{2}} \Rightarrow\left(\frac{b}{a}\right)^{2}+\left(\frac{c}{a}\right)^{2}=1 . \text { Nos parênteses encontramos as razões definidas }
\end{gathered}
$$
anteriormente. Assim, teremos: 


$$
\operatorname{sen}^{2} x+\cos ^{2} x=1
$$

Podemos ainda obter outras duas identidades trigonométricas bastante úteis, apenas dividindo os membros da identidade anterior por $\cos ^{2} x$ e $\operatorname{sen}^{2} x$ :

$$
\begin{aligned}
& \frac{\operatorname{sen}^{2} x}{\cos ^{2} x}+\frac{\cos ^{2} x}{\cos ^{2} x}=\frac{1}{\cos ^{2} x} \Rightarrow \operatorname{tg}^{2} x+1=\sec ^{2} x \\
& \frac{\operatorname{sen}^{2} x}{\operatorname{sen}^{2} x}+\frac{\cos ^{2} x}{\operatorname{sen}^{2} x}=\frac{1}{\operatorname{sen}^{2} x} \Rightarrow 1+\operatorname{cotg}^{2} x=\cos \sec ^{2} x
\end{aligned}
$$

\subsection{Cálculo de alguns ângulos de seno, cosseno e tangente.}

- Ângulos de $30^{\circ}$ e $60^{\circ}$.

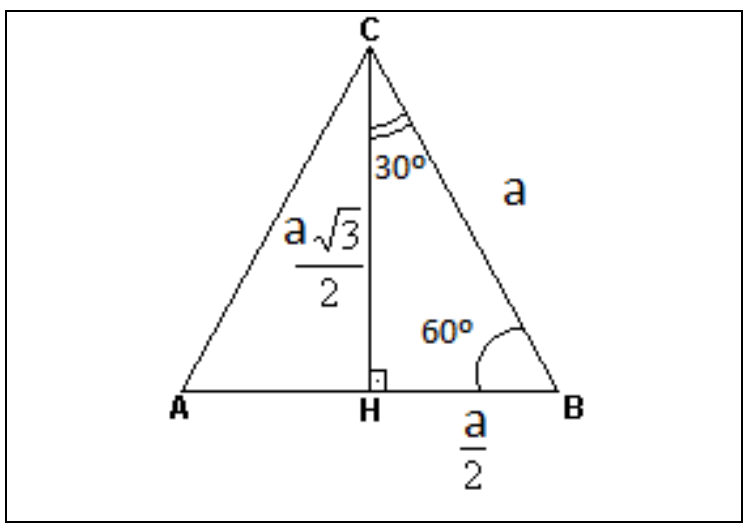

$$
\begin{aligned}
& \operatorname{sen} 30^{\circ}=\frac{\frac{a}{2}}{a}=\frac{a}{2} \cdot \frac{1}{a}=\frac{1}{2} \\
& \cos 30^{\circ}=\frac{\frac{a \sqrt{3}}{2}}{a}=\frac{a \sqrt{3}}{2} \cdot \frac{1}{a}=\frac{\sqrt{3}}{2} \\
& \operatorname{tg} 30^{\circ}=\frac{\frac{a}{2}}{\frac{a \sqrt{3}}{2}}=\frac{a}{2} \cdot \frac{1}{a \sqrt{3}}=\frac{1}{\sqrt{3}}=\frac{\sqrt{3}}{3} \\
& \operatorname{sen} 60^{\circ}=\frac{\frac{a \sqrt{3}}{2}}{\cos 60^{\circ}}=\frac{\frac{a \sqrt{3}}{2} \cdot \frac{1}{a}=\frac{\sqrt{3}}{2}}{\lg }=\frac{1}{a}=\frac{1}{2} \\
& \operatorname{tg} 60^{\circ}=\frac{\frac{a}{2}}{\frac{a}{2}}=\frac{a \sqrt{3}}{2} \cdot \frac{2}{a}=\sqrt{3}
\end{aligned}
$$

Figura 8 - Ângulos de $30^{\circ}$ e $60^{\circ}$ graus. Fonte: Autoria própria 
- Ângulo de $45^{\circ}$

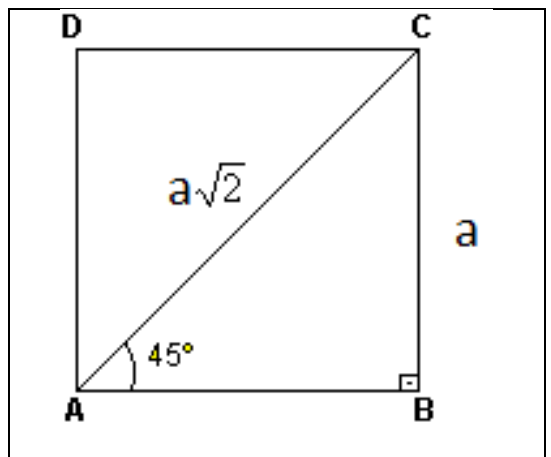

$$
\begin{aligned}
& \operatorname{sen} 45^{\circ}=\frac{a}{a \sqrt{2}}=\frac{1}{\sqrt{2}}=\frac{\sqrt{2}}{2} \\
& \cos 45^{\circ}=\frac{a}{a \sqrt{2}}=\frac{1}{\sqrt{2}}=\frac{\sqrt{2}}{2} \\
& \operatorname{tg} 45^{\circ}=\frac{a}{a}=1
\end{aligned}
$$

Figura 9 - Ângulo de $45^{\circ}$ graus Fonte: Autoria própria

\subsection{Adição de arcos}

Consideremos a circunferência trigonométrica, de centro $\mathrm{O}(0,0)$ e raio unitário.

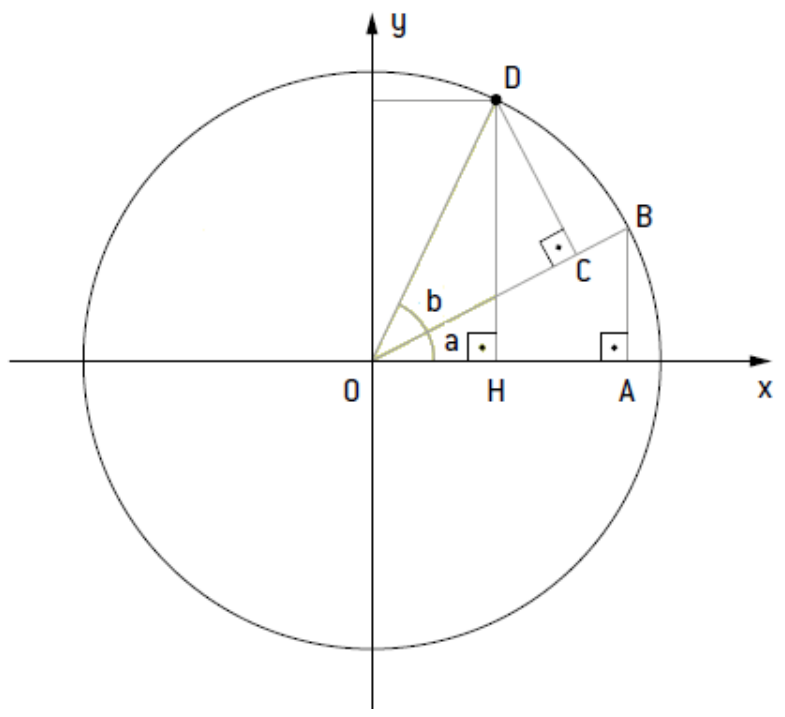

Figura 10 - Circunferência Soma de arcos

Fonte: Autoria própria

Do triângulo $\triangle \mathrm{AHD}$, temos:

$\operatorname{sen}(a+b)=\frac{D H}{O D}=D H$ 
$\cos (a+b)=\frac{O H}{O D}=O H$

E do triângulo $\triangle \mathrm{OCD}$ :

$\operatorname{sen}(b)=\frac{C D}{O D}=C D$

$\cos (b)=\frac{O C}{O D}=O C$

$\mathrm{Na}$ figura, ainda temos que os ângulos $\mathrm{AOB}=\mathrm{CDH}=\mathrm{a}$, já que, $\mathrm{CD}$ e $\mathrm{DH}$ são, respectivamente, perpendiculares aos lados OB e DH. Assim, temos:

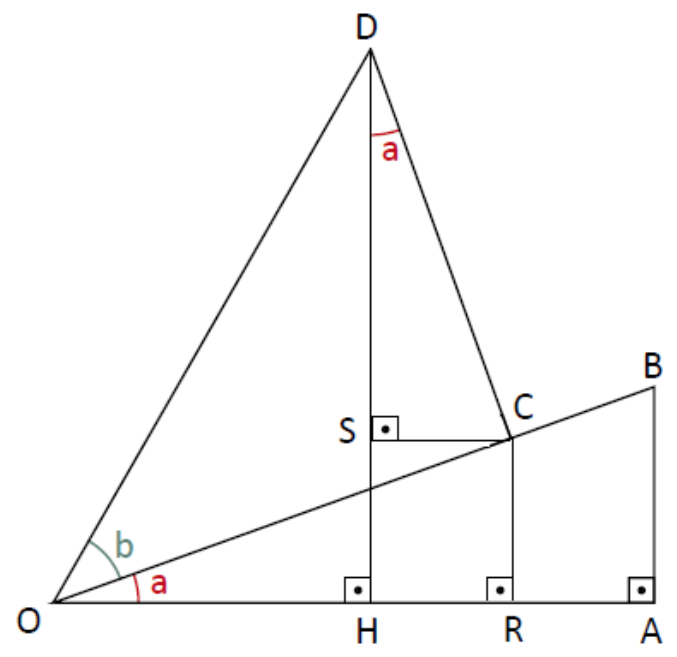

Figura 11 - Triângulo soma de arcos

Fonte: Autoria própria

Do triângulo $\triangle \mathrm{CDS}$ e $\triangle \mathrm{OCR}$, ainda temos:

$$
\begin{aligned}
& \cos (a)=\frac{D S}{C D}=\frac{D S}{\operatorname{sen}(b)} \Rightarrow D S=\cos (a) \cdot \operatorname{sen}(b) \\
& \operatorname{sen}(a)=\frac{C R}{O C}=\frac{C R}{\cos (b)} \Rightarrow C R=\cos (b) \cdot \operatorname{sen}(a) \\
& \operatorname{sen}(a)=\frac{C S}{C D}=\frac{C S}{\operatorname{sen}(b)} \Rightarrow C S=\operatorname{sen}(a) \cdot \operatorname{sen}(b)
\end{aligned}
$$




$$
\cos (a)=\frac{O R}{O C}=\frac{O R}{\cos (b)} \Rightarrow O R=\cos (a) \cdot \cos (b)
$$

Logo deduzimos, obtemos que:

$$
\cos (a+b)=O R-C S \Rightarrow D S=\cos (a+b)=\cos (a) \cos (b)-\operatorname{sen}(a) \operatorname{sen}(b)
$$

Tomando $-\mathrm{b}$ em vez de $\mathrm{b}$ na expressão acima, e $\operatorname{como} \cos (-\mathrm{b})=\cos (\mathrm{b})$ e $\operatorname{sen}(-\mathrm{b})=$ -sen(b), obtemos:

$$
\cos (a-b)=\cos (a) \cos (b)+\operatorname{sen}(a) \operatorname{sen}(b)
$$

Além disso, como :

$\operatorname{sen}\left(\frac{\pi}{2}+\alpha\right)=\cos (\alpha)$ e $\cos \left(\frac{\pi}{2}+\alpha\right)=-\operatorname{sen}(\alpha)$

Assim:

$\operatorname{sen}(a+b)=-\cos \left(\frac{\pi}{2}+a+b\right)=-\cos \left(\frac{\pi}{2}+a\right) \cos (\mathrm{b})+\operatorname{sen}\left(\frac{\pi}{2}+a\right) \operatorname{sen}(\mathrm{b})$

Ou seja:

$$
\operatorname{sen}(a+b)=\operatorname{sen}(a) \cos (\mathrm{b})+\operatorname{sen}(b) \cos (\mathrm{a})
$$

E ainda

$$
\operatorname{sen}(a-b)=\operatorname{sen}(a) \cos (\mathrm{b})-\operatorname{sen}(b) \cos (\mathrm{a})
$$

Deduzidas as somas de diferenças de arcos para seno e cosseno, podemos ainda fazer a mesma coisa para a soma e diferença de arcos da tangente. 


$$
\begin{aligned}
& \operatorname{tg}(a+b)=\frac{\operatorname{sen}(a+b)}{\cos (a+b)}=\frac{\operatorname{sen} a \cos b+\operatorname{sen} b \cdot \cos a}{\cos a \cos b-\operatorname{sen} a \operatorname{sen} b}=\frac{\frac{\operatorname{sen} a \cos b}{\cos a \cos b}+\frac{\operatorname{sen} b \cos a}{\cos a \cos b}}{\frac{\cos a \cos b}{\cos a \cos b}-\frac{\operatorname{sen} a \operatorname{sen} b}{\cos a \cos b}}= \\
& =\frac{\frac{\operatorname{sen} a}{\cos a}+\frac{\operatorname{sen} b}{\cos b}}{1-\frac{\operatorname{sen} a \operatorname{sen} b}{\cos a \cos b}}=\frac{\operatorname{tg} a+\operatorname{tg} b}{1-\operatorname{tg} a \operatorname{tg} b} .
\end{aligned}
$$

Ou seja,

$$
\operatorname{tg}(a+b)=\frac{\operatorname{tg} a+\operatorname{tg} b}{1-\operatorname{tg} a \operatorname{tg} b}
$$

$$
\begin{aligned}
& \operatorname{tg}(a-b)=\frac{\operatorname{sen}(a-b)}{\cos (a-b)}=\frac{\operatorname{sen} a \cos b-\operatorname{sen} b \cdot \cos a}{\cos a \cos b+\operatorname{sen} a \operatorname{sen} b}=\frac{\frac{\operatorname{sen} a \cos b}{\cos a \cos b}-\frac{\operatorname{sen} b \cdot \cos a}{\cos a \cos b}}{\frac{\cos a \cos b}{\cos a \cos b}+\frac{\operatorname{sen} a \operatorname{sen} b}{\cos a \cos b}}= \\
& =\frac{\frac{\operatorname{sen} a}{\cos a}-\frac{\operatorname{sen} b}{\cos b}}{1+\frac{\operatorname{sen} a \operatorname{sen} b}{\cos a \cos b}}=\frac{\operatorname{tg} a-\operatorname{tg} b}{1+\operatorname{tgatg} b} .
\end{aligned}
$$

Com isso temos,

$$
\operatorname{tg}(a-b)=\frac{\operatorname{tg} a-\operatorname{tg} b}{1+\operatorname{tg} a \operatorname{tg} b} .
$$

\section{Arco duplo e prostaférese}

Das relações obtidas anteriormente, podemos ainda estabelecer as relações do arco duplo. Pois:

$$
\operatorname{sen}(a+b)=\operatorname{sen}(a) \cos (b)+\operatorname{sen}(b) \cos (a)
$$

Fazendo a=b, na relação anterior:

$$
\operatorname{sen}(a+a)=\operatorname{sen}(a) \cos (a)+\operatorname{sen}(a) \cos (a)
$$

$$
\operatorname{sen}(2 a)=2 \operatorname{sen}(a) \cos (a)
$$


Da mesma forma, usando o mesmo raciocínio na relação do cosseno da adição:

$$
\cos (a+a)=\cos a \cdot \cos a-\operatorname{sen} a \cdot \operatorname{sen} a \Rightarrow \cos (2 a)=\cos ^{2} a-\operatorname{sen}^{2} a
$$

$$
\cos (2 a)=\cos ^{2} a-\operatorname{sen}^{2} a
$$

Podendo assumir ainda, devido à identidade $\cos ^{2} a+\operatorname{sen}^{2} a=1$, as formas:

$$
\begin{aligned}
& \cos (2 a)=1-2 \operatorname{sen}^{2} a \quad e \\
& \cos (2 a)=2 \cos ^{2} a+1
\end{aligned}
$$

Podemos também, com base na relação da tangente da adição:

$$
\operatorname{tg}(a+b)=\frac{\operatorname{tg} a+\operatorname{tg} b}{1-\operatorname{tg} a \operatorname{tg} b} \Rightarrow \operatorname{tg}(2 a)=\frac{2 \operatorname{tg} a}{1-\operatorname{tg}^{2} a}
$$

$$
\operatorname{tg}(2 a)=\frac{2 \operatorname{tg} a}{1-\operatorname{tg}^{2} a}
$$

Utilizando as relações/identidades, podemos deduzir fórmulas que permitem fatorar expressões trigonométricas conhecidas como fórmulas de prostaférese - palavra de origem grega cujo significado é adição/subtração. Essas fórmulas são úteis na fatoração de expressões trigonométricas, pois podemos simplificá-las e efetuar os cálculos de forma mais simples.

Fórmulas de prostaférese

$$
\left\{\begin{array}{l}
\operatorname{sen}(a+b)=\operatorname{sen}(a) \cos (b)+\operatorname{sen}(b) \cos (a) \\
\operatorname{sen}(a-b)=\operatorname{sen}(a) \cos (b)-\operatorname{sen}(b) \cos (a)
\end{array}\right.
$$

Somando-se ambos os membros, teremos:

$$
\begin{aligned}
& \operatorname{sen}(a+b)+\operatorname{sen}(a-b)=\operatorname{sen}(a) \cos (b)+\operatorname{sen}(b) \cos (a)+\operatorname{sen}(a) \cos (b)-\operatorname{sen}(b) \cos (a) \Rightarrow \\
& \operatorname{sen}(a+b)+\operatorname{sen}(a-b)=\operatorname{sen}(a) \cos (b)+\operatorname{sen}(a) \cos (b) \Rightarrow \\
& \operatorname{sen}(a+b)+\operatorname{sen}(a-b)=2 \operatorname{sen}(a) \cos (b)
\end{aligned}
$$


Realizando a mudanças das variáveis: $\left\{\begin{array}{l}(a+b)=p \\ (a-b)=q\end{array} \Rightarrow\left\{\begin{array}{l}a=\frac{p+q}{2} \\ b=\frac{p-q}{2}\end{array}\right.\right.$

Obtemos:

$$
\operatorname{sen} p+\operatorname{sen} q=2 \operatorname{sen}\left(\frac{p+q}{2}\right) \cos \left(\frac{p-q}{2}\right)
$$

De modo análogo, encontramos ainda que:

$$
\begin{aligned}
& \operatorname{sen} p-\operatorname{sen} q=2 \operatorname{sen}\left(\frac{p-q}{2}\right) \cos \left(\frac{p+q}{2}\right) \\
& \cos p+\cos q=2 \cos \left(\frac{p+q}{2}\right) \cos \left(\frac{p-q}{2}\right) \\
& \cos p-\cos q=-2 \operatorname{sen}\left(\frac{p+q}{2}\right) \operatorname{sen}\left(\frac{p-q}{2}\right) \\
& \operatorname{sen} p+\operatorname{sen} q=2 \operatorname{sen}\left(\frac{p+q}{2}\right) \cos \left(\frac{p-q}{2}\right) .
\end{aligned}
$$

\subsection{Teorema dos senos}

Em qualquer triângulo $\triangle \mathrm{ABC}$, as medidas dos lados são diretamente proporcionais aos senos dos ângulos opostos, sendo a constante de proporcionalidade igual à medida do diâmetro da circunferência circunscrita ao triângulo. 


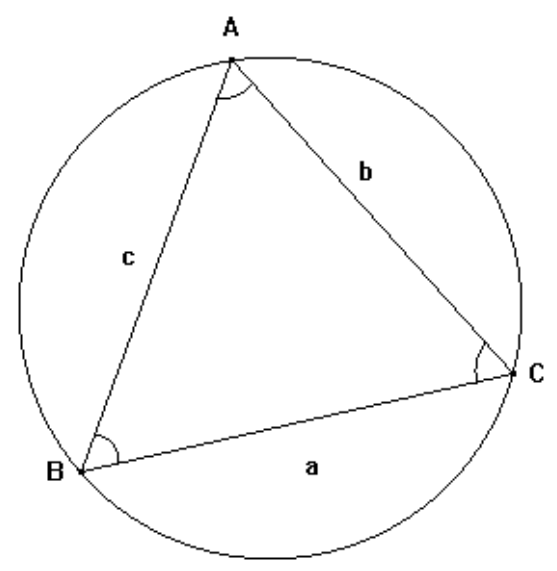

Figura 12 - Teorema dos senos Fonte: Autoria própria

Vejamos a demonstração para um triângulo acutângulo $\triangle \mathrm{ABC}$, de lados a, b e c, inscrito numa circunferência de centro $\mathrm{O}$.

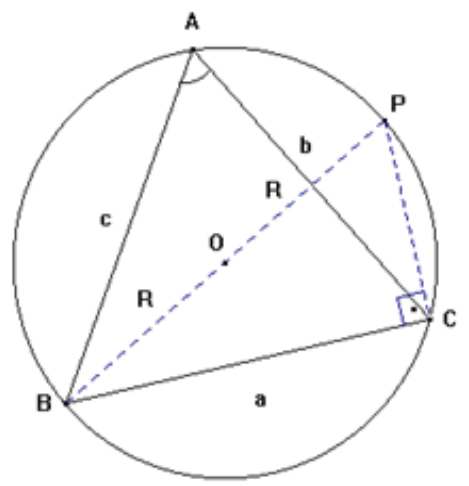

Figura 13 - Teorema dos senos 2 Fonte: Autoria própria
Traçando o diâmetro $\mathrm{BD}$, obtemos um triângulo retângulo $\triangle \mathrm{BPC}$, retângulo $\mathrm{C}$, pois BP é diâmetro.

Notamos que os ângulos $B \hat{A} C$ e $B \hat{P} C$, são iguais, por serem inscrito com o mesmo arco $B C$.

Assim: $\operatorname{sen} \hat{P}=\frac{a}{2 R}$ e como os ângulos $B \hat{A} C$ e $B \hat{P} C$, são iguais, temos que $\operatorname{sen} \hat{A}=\frac{a}{2 R} \Rightarrow \frac{a}{\operatorname{sen} \hat{A}}=2 R$

Da mesma forma obtemos: $\frac{b}{\operatorname{sen} \hat{B}}=2 R$ e $\frac{c}{\operatorname{sen} \hat{C}}=2 R$

Comparando as igualdades, obtemos:

$$
\frac{a}{\operatorname{sen} \hat{A}}=\frac{b}{\operatorname{sen} \hat{B}}=\frac{c}{\operatorname{sen} \hat{C}}=2 R
$$

Analogamente, concluímos que a relação também é válida nos triângulos obtusângulo e retângulo.

\subsection{Teorema dos cossenos}

Para qualquer triângulo $\triangle \mathrm{ABC}$, o quadrado da medida de um lado é igual à soma dos quadrados das medidas dos outros dois lados, menos o dobro do produto dessas medidas pelo cosseno do ângulo compreendido por eles. 


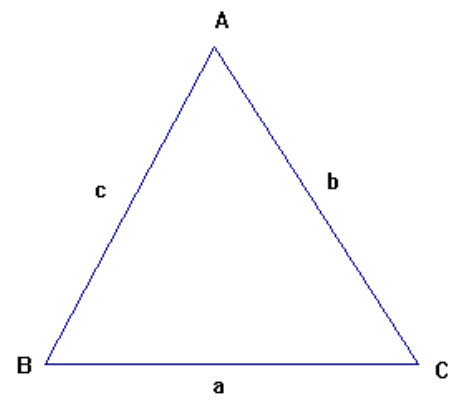

$$
\begin{aligned}
& a^{2}=b^{2}+c^{2}-2 b c \cdot \cos \hat{A} \\
& b^{2}=a^{2}+c^{2}-2 a c \cdot \cos \hat{B} \\
& c^{2}=a^{2}+b^{2}-2 a b \cdot \cos \hat{C}
\end{aligned}
$$

Figura 14 - Teorema dos cossenos

Fonte: Autoria própria

Vamos demonstrar a primeira relação, considerando o ângulo A agudo, as demonstrações das outras relações podemos obter de modo análogo.

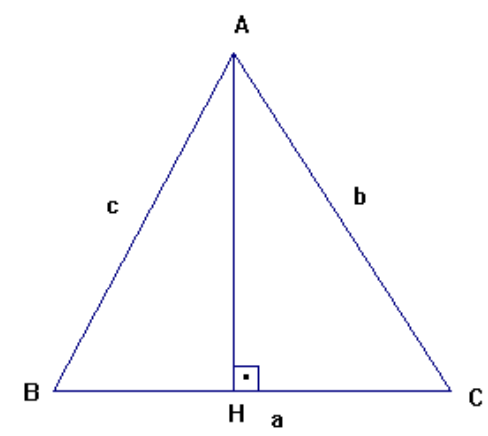

Figura 15 - Teorema dos cossenos 2 Fonte: Autoria própria

Traçando a altura $\mathrm{BH}$, teremos os triângulos retângulos $\triangle \mathrm{ABH}$ e $\Delta \mathrm{CBH}$. No triângulo $\triangle \mathrm{ABH}$, temos:

$$
\left\{\begin{array}{c}
\cos \hat{A}=\frac{A H}{c} \Rightarrow A H=c \cdot \operatorname{sen} \hat{A} \\
c^{2}=h^{2}+A H^{2} \Rightarrow h^{2}=c^{2}-A H^{2} \Rightarrow h^{2}=c^{2}-(c \cdot \cos \hat{A})^{2} \Rightarrow \\
\Rightarrow h^{2}=c^{2}-c^{2} \cdot \cos ^{2} \hat{A}(I)
\end{array}\right.
$$


No triângulo $\triangle \mathrm{CBH}$, temos:

$$
\left\{\begin{array}{c}
a^{2}=h^{2}+C H^{2} \Rightarrow a^{2}=h^{2}-(b-A H)^{2} \Rightarrow \\
\quad \Rightarrow h^{2}=a^{2}-(b-c \cdot \cos \hat{A})^{2} \Rightarrow \\
\Rightarrow h^{2}=a^{2}-b^{2}+2 b c \cdot \cos \hat{A}-2 b c \cdot \cos \hat{A}(I I)
\end{array}\right.
$$

De (I) e (II) temos:

$$
\begin{aligned}
& a^{2}-b^{2}+2 b c \cdot \cos \hat{A}-2 b c \cdot \cos \hat{A}=c^{2}-c^{2} \cdot \cos ^{2} \hat{A} \Rightarrow \\
& \Rightarrow a^{2}=b^{2}+c^{2}-2 b c \cdot \cos \hat{A}
\end{aligned}
$$

No capítulo a seguir abordamos o referencial teórico utilizado nesta pesquisa. 


\section{Capítulo 2}

Neste Capítulo, apresentamos o referencial teórico utilizado durante as análises desta pesquisa: perspectivas de ensino com maior frequência nas práticas dos professores; tipologias e as funções atribuídas às provas matemáticas. A discussão teórica nos revelaram indicações e permitiram reflexões para alcançar os objetivos propostos.

\section{Educação Matemática}

A Educação Matemática tem ao longo dos anos desenvolvido inúmeras pesquisas buscando compreender melhor os processos de ensino e aprendizagem de matemática em todos os níveis de ensino - além de temáticas que os permeiam, como os currículos, materiais didáticos, avaliação, emprego de tecnologias no seu ensino, a prática e desenvolvimento docente, entre outras.

\subsection{Matemática}

Apesar da matemática ser mais antiga que a civilização - já que foram encontrados vários registros matemáticos em pedras, ossos e moldes de barro de uma época em que os agrupamentos humanos nem a escrita dominavam ainda - os livros de história da matemática pontam a antiga Grécia como o berço da matemática abstrata. A obra de Euclides de Alexandria (360 a.C. - 295 a.C.), conhecida como os Elementos de Euclides, foi o modelo mais significativo, já que reuniu todo o conhecimento matemático produzido pelos grandes matemáticos até a sua época.

O modelo utilizado por Euclides é a sucessão de inferências lógicas a partir de axiomas ou proposições aceitas previamente, sendo vista como a forma de verificação da verdade. Nesse modelo, só se pode saber da verdade de um teorema e conhecê-lo mediante uma demonstração, sendo a essência verdadeira da matemática.

As hipóteses do florescimento das demonstrações matemáticas terem surgido na Grécia Antiga se apoiam na atmosfera racionalista lá encontrada, na participação no jogo político, por ela ter sido o berço da Democracia, onde pela primeira vez os cidadãos participaram diretamente dos debates dos assuntos do Estado.

Para Arsac (1987) esse clima de debate argumentativo na cidade grande poderia ter servido de base para a transformação da matemática em uma ciência hipotético-dedutiva, 
hipótese externalista. Ou ainda ter sido essa transformação consequência direta de problemas da incomensurabilidade, a partir da escola Pitagórica, hipótese internalista. (ARSAC, 1987, p.271). Arsac conclui que sem o problema da irracionalidade, a transformação da matemática não teria ocorrido, mesmo na sociedade grega e ainda num outro contexto social, mesmo diante do mesmo problema, a matemática não teria mudado da mesma forma. (ARSAC, 1987, p.298 e 2007, p.39).

As demonstrações presentes na obra de Euclides se tornaram uma referência para toda a matemática e ainda de modelo pedagógico até a modernidade europeia. No entanto, as controvérsias e dúvidas quanto a validade do quinto postulado ${ }^{1}$ (das retas paralelas) serviram de base para o surgimentos de outras geometrias, as geometrias não euclidianas, igualmente coerentes.

Devido ao abalo causado pelo quinto postulado na certeza matemática, conhecida como a crise dos fundamentos, ocorreu uma grande corrida na busca de fundamentos para ela, sendo as principais soluções apresentadas: O logicismo, o intuicionismo e o formalismo.

O logicismo defendia que a lógica era um ramo da matemática e pretendiam reduzir todos os conceitos matemáticos a conceitos lógicos. Já o intucionismo defendia que a matemática teria de ser desenvolvida apenas por métodos construtivos finitos sobre a sequência dos números naturais, dada intuitivamente. E o formalismo pretendia organizar toda a matemática numa estrutura lógica.

Essa três propostas, mesmo com avanços e retrocessos, influenciaram e ainda influenciam toda a matemática, e consequentemente a concepção ${ }^{2}$ que o professor dessa disciplina constrói sobre a matemática e consequentemente seu ensino aprendizagem.

\footnotetext{
${ }^{1}$ Por um ponto não contido em uma reta dada, pode ser traçada uma e apenas uma reta paralela à reta dada.

${ }^{2}$ Estrutura mental que abrange crenças, conceitos, significados, proposições, regras, imagens mentais, preferências e gostos. Logo a concepção do professor é formada pelas experiências e relações pessoais ao longo de toda sua vida.
} 


\subsection{Concepções}

As concepções que os professores de matemática possuem sobre a matemática, seu ensino e sua aprendizagem exerce uma grande influência na sua prática de ensino. Assim investigando sobre o tema, encontramos o trabalho de Kubs e Ball (1986), citados por Thompson (1992) que abordam as perspectivas de ensino que surgem com maior frequência nas práticas dos professores, bem como a visão da matemática que usualmente lhe está associada.

Esses autores explicitam quatro visões sobre o ensino da matemática com maior frequência nas práticas dos professores. A saber: a focada no aluno, no conteúdo com ênfase no entendimento conceitual, no conteúdo com ênfase no desempenho e na sala de aula.

Focada no aluno: ensino da matemática que focaliza na construção individual do conhecimento matemático do aluno, numa visão construtivista. $\mathrm{O}$ aluno possui um papel ativo em todo o processo, cabendo ao professor criar o ambiente de atividades matemáticas que possibilitem a exploração, defesa e validação das ideias matemáticas por parte dos alunos. $\mathrm{O}$ professor é visto como um facilitador da aprendizagem do aluno.

No conteúdo com ênfase no entendimento conceitual: onde o foco é o conteúdo matemático, mesmo que exista uma preocupação de privilegiar o desenvolvimento da compreensão conceitual dos alunos acerca das ideias e processos matemáticos, dando-se ênfase às relações lógicas subjacentes. Trata-se de uma visão formalista. Ao professor, cabe o papel de sequenciar as ideias e os processos matemáticos que devem ser ensinados.

No conteúdo com ênfase no desempenho: o foco continua no conteúdo matemático, apresentado de forma organizada, hierarquizada e sequencial ao aluno, ou seja, o foco são as

regras e fórmulas que podem ser utilizados para resolver problemas. É uma visão instrumental da matemática. Espera-se do aluno um bom conhecimento das regras e procedimentos que lhes serão úteis. O professor tem a função de expor os conteúdos matemáticos de forma sequencial e exemplificada.

Na sala de aula: ensino da matemática baseado no conhecimento efetivo da classe (p. 136). O conteúdo matemático não assume importância relevante. $\mathrm{O}$ aspecto fundamental é garantir aulas que mantenham os alunos efetivamente envolvidos num trabalho, conforme os 
currículos estabelecidos. Não está associada a qualquer visão sobre o ensino da matemática pelos pesquisadores. Ao professor, cabe estruturar e conduzir as atividades.

Acreditamos que o acompanhamento das aulas dos professores, ou seja, de sua prática diária, permita, de maneira mais clara, perceber as suas concepções, o papel que o aluno deve exercer e a abordagem dos conteúdos matemáticos - o que não poderíamos perceber apenas por seus discursos, que acreditamos receberem grande influência social, além de outros fatores extraclasse.

\subsection{Provas Matemáticas}

Várias são as pesquisas internacionais encontradas associadas às provas matemáticas e, de forma geral, elas são elaboradas focalizadas em quatro perspectivas gerais: Didática, Epistemológica, Histórica, filosófica e Cognitiva.

Quanto ao ensino e aprendizagem das provas matemáticas, essas pesquisas tanto focam nas dificuldades dos professores (Almouloud, 2006), como na formação de professores (Garnica, 1995 e Pietropaolo, 2005), e ainda nas funções e tipologias das provas matemáticas Balacheff (1987, 2000), De Villiers (1990,1993, 2001), Harel e Sowder (2007). As pesquisas apontam que as provas matemáticas permeiam os objetos matemáticos, sendo um processo possível de ser ensinado/aprendido.

O pesquisador Almouloud (2006), que há muito tempo pesquisa as provas matemáticas e acompanha a formação continuada de professores da rede pública de São Paulo, chama a atenção para as dificuldades dos professores sobre a temática e os entraves do seu ensino e aprendizagem na educação básica.

O papel da prova rigorosa na formação do professor foi objeto da pesquisa de Garnica (1995). Na busca pelo significado da prova rigorosa na formação do professor de matemática, o autor identifica sua importância, distinguindo e identificando duas leituras para ela: a primeira, de natureza técnica, procedimental, ligada diretamente à prática científica da matemática; e a outra, de natureza crítica, reflexiva, que para o autor deve ser integrada por meio de motivações que levantem abordagens históricas e filosóficas, de modo a permitir um esclarecimento quanto à forma de criação e divulgação das concepções que permeiam o fazer matemático, relativizando a ideia de rigor, mais próximo do ensino e aprendizagem na educação básica. 
A pesquisa de Pietropaolo (2005) teve como objetivo procurar compreensões sobre a necessidade e a acessibilidade da implementação de provas e demonstrações nos currículos de matemática da educação básica e ainda investigar as implicações que essa inovação traz aos currículos de formação inicial de professores. Sua proposta é de uma (re)significação das provas nos currículos da educação básica e nos de formação de professores.

Em suas entrevistas com professores, de todos os níveis de ensino, Pietropaolo (2005) encontrou um consenso: a riqueza da prova, no sentido amplo da palavra, como um conteúdo e também como recurso pedagógico na educação básica e ainda a necessidade de uma formação do professor que permitisse envolver seus alunos em todo o processo e não apenas a simples reprodução em sala de aula.

Mesmo sabendo que os professores desenvolvem durante a atividade docente competências para elaborar e desenvolver situações de aprendizagem envolvendo provas, é inegável que uma formação inicial e continuada é necessária para o pleno desenvolvimento profissional do professor, em especial no que se refere às provas matemáticas.

\subsubsection{Funções e Tipologias}

As funções das provas matemáticas vão além da simples verificação dos resultados matemáticos, ou seja, existem outros objetivos além de assegurar a verdade de uma afirmação ou "verificação". Por exemplo:

A "iluminação", quando além de assegurar a verdade de uma afirmação matemática, permite entender por que ela é correta.

A "sistematização", quando permite a organização das provas matemáticas anunciadas num sistema de axiomas, definições e outros teoremas.

Nas pesquisas de De Villiers (1990,1993, 2001) encontramos uma ampliação das funções das provas matemáticas. O autor expõe algumas funções das provas dentro da atividade matemática, buscando descrever motivações e objetivos a serem alcançados no ensino e aprendizagem, tornando-os mais significativos. Aponta como funções das provas:

- Verificação, vista pela maioria como a única forma do matemático alcançar a certeza/convicção das propriedades matemáticas - utilizada quando precisamos nos convencer ou convencer alguém da verdade de uma afirmação. Muitas vezes, é depois de empregar o 
raciocínio indutivo, que se chega à convicção de que algo é verdadeiro, resultando em incentivo para a busca da sua demonstração.

- Sistematização, pela organização dos diversos resultados conhecidos num sistema dedutivo, partindo de conceitos básicos ou axiomas e regras estabelecidas - pode servir para apontar inconsistência.

- Descobrimento, por permitir obter novos resultados dedutivamente - encontramos descobertas matemáticas que emergiram de processos puramente dedutivos e não apenas da intuição ou métodos empíricos.

- Comunicação, pela forma eficaz de transmissão dos conhecimentos matemáticos encontramos aqui uma forte dimensão social, não fugindo nem mesmo a demonstração matemática, do contexto social e da negociação dos conceitos em jogo.

- Desafio intelectual, proporcionado na construção de uma prova matemática e pela grande engenhosidade necessária ao matemático para obter sucesso.

- Explicação, pela exibição dos motivos, razões das verdades apresentadas. Essa função é atingida quando a prova fornece os indícios do porquê ela é verdadeira, característica apontada por matemáticos e educadores matemáticos como o aspecto mais importante das provas matemáticas.

De Villiers (2001) defende no ensino e aprendizagem a abordagem da dúvida como uma forma eficiente de fazer os alunos avançarem na elaboração de justificativas em matemática. Para o autor, os alunos precisam sentir a necessidade de provar, justificar e convencer o outro a respeito de suas afirmações. Apresentar os motivos pelos quais acredita ser a afirmação correta, não só para se convencer, mas também para convencer o outro, dividir com o outro a sensação da certeza, deixando explícito por que acredita como chegou a uma dada conclusão e o que respalda sua convicção.

Ainda com relação aos trabalhos buscando a abordagem das provas matemáticas na educação básica, encontramos a pesquisadora Hanna (2001), que defende, dentre todas as funções existentes nas provas matemáticas, a importância fundamental da função explicativa para a educação escolar. Para isso, ela faz a distinção entre as provas que provam e as que explicam, defende a importância desta última como primordial para o ensino, sendo o grande 
desafio encontrar formas mais efetivas de usar as provas matemáticas para promover a compreensão matemática em sala de aula.

Quanto às tipologias das provas matemáticas, encontramos pesquisadores que apresentam uma classificação daquelas elaboradas pelos alunos. Um deles, Balacheff (1987, 2000), distingue entre provas pragmáticas e provas intelectuais.

Os trabalhos de Balacheff são particularmente relevantes, pois neles encontramos definições de alguns termos importantes, os quais adotamos neste trabalho, como “explicação", "provas” e "demonstração". O termo "explicação" é uma ideia primitiva da qual deriva os termos prova e demonstração. A seguir, descrevemos os termos definidos e hierarquizados, denominados tipos de sofisticações de provas.

- Na explicação, busca-se o convencimento a partir da explicitação do caráter verdadeiro, da afirmação em que as razões expostas podem ser discutidas, refutadas ou aceitas.

- A prova é constituída por explicações aceitas por certa comunidade, num certo momento, que pode ser objeto de um debate.

- A demonstração é uma prova que segue regras determinadas e são aceitas pela comunidade matemática, ou seja, obtida a partir das que a antecedem por um processo dedutivo, usando um conjunto de regras bem definidas.

No trabalho de Balacheff (1987), encontramos sua investigação sobre os processos de provas que apresentaram alunos adolescentes de 12 a 15 anos. $\mathrm{O}$ autor estudou os argumentos utilizados pelos alunos para seu próprio convencimento, chegando às categorias: "Provas Pragmáticas" e "Provas Intelectuais". Para o autor, os alunos usam provas pragmáticas quando utilizam a ação (baseados em manipulações ou exemplos concretos) e as provas intelectuais quando se utilizam de ações interiorizadas (baseadas em formulações abstratas de propriedades matemáticas e de relações entre elas).

Essas duas categorias propostas por Balacheff (1987) ainda são subdivididas em quatro tipos, nesta ordem e hierarquia, a saber:

1. Empirismo ingênuo - é o tipo de prova mais simples. Nele, os alunos afirmam a validade da propriedade, depois de verificar apenas alguns exemplos; 
2. Experiência crucial - nesse caso os alunos elegem minuciosamente um exemplo, mas, ao contrário do empirismo ingênuo, tentam, explicitamente, generalizar a propriedade. Mesmo verificando em um caso particular, não o consideram tão particular, acreditando poder ser geral;

3. Exemplo genérico - nesse tipo de prova, e os alunos utilizam um caso específico para representar todos os casos possíveis em um argumento geral; e

4. Experiência mental - na qual os alunos utilizam apenas raciocínios interiorizados e não mais ligados à ação, verificação concreta.

Nos trabalhos de Balacheff ainda obtemos uma descrição de cada um desses tipos de provas, obtidas após análise das respostas apontadas pelos alunos a um problema que envolve o número de diagonais de um polígono. Para Balacheff (1987), o empirismo ingênuo e a experiência crucial estão categorizados como provas pragmáticas. Já a experiência mental está categorizada como prova intelectual. O exemplo genérico é classificado ora em provas pragmáticas, ora como provas intelectuais.

Enquanto Balacheff (1987) toma como base a relação entre sujeito e processo de validação, pesquisadores como Harel e Sowder (2007) utilizam uma categorização tomando como referência o estudante, produtos individuais, denominado Proof Schemes - esquemas de prova, que são tipos de justificativas que convencem os estudantes e que eles utilizam para convencer os outros colegas e o professor.

Para a definição de "esquema de prova", Harel e Sowder (2007, p. 808-809) apoiam-se em três definições:

1. Conjectura versus fato: a afirmação pode ser concebida pelo indivíduo como uma conjectura ou um fato. Como conjectura, quando faz uma afirmação cuja verdade é incerta, deixando de ser conjectura para tornar-se um fato - quando para o indivíduo a afirmação se torna verdadeira.

2. Provar: é o processo utilizado por um indivíduo (ou uma comunidade) para remover dúvidas sobre a verdade de uma afirmação. Esse processo engloba dois subprocessos: verificar e convencer.

3. Verificar versus convencer: verificar é o processo que um indivíduo (ou uma comunidade) emprega para remover as suas próprias dúvidas sobre a verdade de uma 
afirmação. Convencer, persuadir, é o processo que um indivíduo (ou comunidade) emprega para remover as dúvidas dos outros sobre a verdade de uma afirmação.

Então, não basta para a matemática um procedimento de prova fazer sentido apenas para o próprio indivíduo, mas também deve o procedimento adotado ser capaz de convencer outros por meio da explicação e justificação das suas conclusões. Esse aspecto de convencimento dos outros, de persuasão, constitui a dimensão pública da demonstração e é uma prática social não só para matemáticos, mas também para quem estuda matemática. Assim, persuadir e convencer são processos subjetivos e provar pode variar de indivíduo para indivíduo, de contexto para contexto, de civilização para civilização e, dentro da mesma civilização, de geração para geração (Harel e Sowder, 2007, p. 809).

Dadas essas considerações, os autores apresentam a definição de esquema de prova de uma pessoa (ou comunidade), consiste em determinar o que constitui verificar e persuadir para essa pessoa (ou comunidade).

Os autores identificam três categorias de esquemas de prova centradas no aluno. São elas: External Conviction Proof Schemes, Empirical Proof Schemes e Analytical Proof Schemes, Harel e Sowder (2007, p. 809).

- External Conviction Proof Schemes (“esquemas de prova por convicção externa”): quando o modo utilizado para validação se refere a uma autoridade externa, por exemplo, "o professor falou”, “está assim no livro didático”, ou ainda pela forma simbólica.

- Empirical Proof Schemes (“esquemas de prova empírica”): quando o modo utilizado para validação são exemplos, pode ser perceptivo: realizado por observações físicas, por exemplo, gráficos; ou indutivo: realizado por experimentações concretas.

- Analytical Proof Schemes (“esquemas de prova analítica ou dedutiva”): quando o modo utilizado para validação se baseia em argumentos abstratos e deduções lógicas, denominado transformativo, que considera os aspectos de generalidade da conjectura, transformando imagens mediante processos dedutivos ou axiomáticos.

Observamos que a classificação de Harel e Sowder (2007) é mais ampla que a de Balacheff (1987), ampliando nossa visão quanto às provas matemáticas.

Esses tipos de raciocínios descritos são importantes, uma vez que se podem identificar os níveis de conhecimentos dos alunos e assim contribuir na orientação e percepções dos 
professores no desenvolvimento de atividades que possibilitem o avanço dos alunos entre os tipos de provas elaboradas até chegarem a provas mais formais. Aqui reside uma questão fundamental: é possível o ensino e aprendizagem das provas matemáticas na educação básica. 


\section{Capítulo 3}

Neste capitulo apresentamos a metodologia adotada para o acompanhamento e análise dos dados. Como buscamos compreender e explorar acontecimentos em contextos complexos, escolhemos o estudo de caso, indicado para essas situações. Esse procedimento nos orientou durante a coleta de dados.

\section{Metodologia}

Estabelecida a questão de pesquisa que é elaborar um estudo de caso a partir do acompanhamento das aulas de professores de matemática de uma escola pública, objetivamos a resposta para as seguintes questões: os professores do ensino médio privilegiam provas matemáticas em suas aulas? De que forma? Que tipologias de provas buscam desenvolver em sala de aulas ou elaboram?

Constatamos em nossas leituras que a pesquisa qualitativa é a mais indicada, para nossos objetivos, pois ela é definida como aquela cujos dados são colhidos diretamente no ambiente natural de maneira que possam ser descritos, tendo como principal instrumento o investigador. As cinco principais características da pesquisa qualitativa são:

- utiliza-se o contexto onde ocorre o fenômeno como fonte direta para obtenção dos dados;

- o pesquisador é considerado instrumento-chave para o desenvolvimento do trabalho;

- a preocupação está no processo e não simplesmente nos resultados e produtos;

- os pesquisadores tendem a analisar seus dados indutivamente, mas o fenômeno pesquisado é explicado dialeticamente de forma indutivo-dedutiva e compreendido em sua totalidade;

- o significado é a preocupação essencial na abordagem qualitativa. (LÜDKE e ANDRÉ, 2007, p. 17).

Por essas características, podemos considerar que na abordagem qualitativa o pesquisador busca, em contato direto com o objeto estudado em sua complexa realidade, coletar dados descritivos com um plano aberto e flexível, de forma natural, valorizando o processo e a visão dos participantes. 


\subsection{Estudo de Caso}

O estudo de caso é indicado quando o pesquisador procura compreender, explorar ou descrever acontecimentos e contextos complexos. Assim, resolvemos adotar esse método qualitativo nesta investigação, pois acreditamos ser a mais adequada para realizar o levantamento das práticas dos professores de matemática, quanto à abordagem das provas matemáticas no Ensino Médio.

Para Yin (2010, p. 39-40), o estudo de caso é uma investigação empírica que investiga um fenômeno no seu ambiente natural, quando as fronteiras entre o fenômeno e o contexto não são bem definidas, ainda utilizando múltiplas fontes de evidência e tendo como objetivos explorar, descrever ou explicar.

O estudo de caso pode ser de caso único ou ainda estudos de mais de um caso, mobilizando um grupo de pesquisa e um aporte financeiro. Os de caso único se baseiam apenas no estudo de um único caso, que é o caso desta pesquisa realizado, em um nível individual e sem aporte financeiro.

Assim, acreditamos ser o estudo de caso o mais adequado para nossa pesquisa, pois nele o pesquisador tem como objetivo revelar uma situação tal como ela é; uma perspectiva interpretativa, pela qual busca descrever a situação pesquisada revelando-a e não intervindo sobre ela. Ademais, procura compreender a situação do ponto de vista dos pesquisados, utilizando múltiplas fontes de evidência indicadas para o estudo de caso, com a combinação de métodos de coleta de dados, tais como: entrevistas, questionários, observações e outros. Este foi um caminho por nós adotado para seguir durante a coleta e análise dos dados nesta pesquisa. Planejamos, dessa forma, seguir os critérios definidos por esse método de pesquisa.

Para uma melhor delimitação da pesquisa devemos saber que o estudo de caso possui algumas características fundamentais, que segundo Lüdke e André (2007, p. 17), são:

- Visa à descoberta;

- Enfatiza a interpretação do contexto;

- Busca retratar a realidade de forma completa e profunda;

- Usa uma variedade de fontes de informações;

- Revela experiência vicária e permite generalização naturalista; e

- Procura representar os diferentes e às vezes conflitantes pontos de vista numa situação social e utiliza uma linguagem acessível. 
Um princípio básico desse tipo de estudo [de caso] é que, para uma apreensão mais completa do objeto, é preciso levar em conta o contexto em que ele se situa. Assim, para compreender melhor a manifestação geral de um problema, as ações, as percepções, os comportamentos e as interações das pessoas devem ser relacionadas à situação específica onde ocorrem ou à problemática determinada a que estão ligadas. (LÜDKE e ANDRÉ, 2007, p. 18).

Ainda de acordo com Lüdke e André (2007), o estudo de caso apresenta algumas fases que são: fase exploratória, delimitação do estudo e análise sistemática.

A exploração começa como um plano inicial que se delineia à medida que o estudo se desenvolve. Já a delimitação representa uma coleta sistemática de informações baseada na seleção de aspectos mais relevantes ao estudo e, finalmente, a análise é a organização, interpretação e disponibilização dos dados e relatos obtidos na pesquisa.

O estudo de caso se mostrou o método mais indicado para adotamos nesta pesquisa, pois temos como objeto de estudo uma entidade bem definida e visamos conhecer melhor os "como" e os "porquê" ocorrem o objeto de estudo, além do uso de uma variedade de instrumentos e estratégias de recolha de dados, e de ter ainda o investigador como principal instrumento desta recolha (Yin, 2010).

Portanto, neste trabalho, adotamos o estudo de caso por proporcionar uma grande vantagem na busca da nossa questão de pesquisa, que é uma maior apreensão da realidade que buscamos compreender com o apoio do referencial teórico. Seguimos, assim, seus princípios para a realização do estudo aqui desenvolvido, desde sua preparação, na coleta de dados e a análise das evidências obtidas. O estudo de caso nos permitirá traçar um plano de desenvolvimento que seguiremos neste trabalho, sempre atentos a: evitar a parcialidade, desenvolver a habilidade de formular boas questões, ser flexível, estar preparado com os assuntos abordados, e ainda, estar preparado para ouvir. (Yin, 2010).

\subsection{Coleta de dados}

Como estratégias para coleta de dados, nesta pesquisa, utilizou-se o maior número possível de informações e dados, como ensinam os princípios do estudo de caso (Yin, 2010). Utilizamos, então, as fontes: observação direta, gravação em áudio, anotações de campo e entrevistas. Dessa forma, tentamos dar um maior rigor aos dados levantados, o que o autor chama de triangulação dos dados, ou seja, a indicação de uma mesma evidência por meio de fontes diferentes. 


\subsection{Observação direta e anotações de campo}

A observação direta e as anotações de campo foram realizadas durante os acompanhamentos das aulas. Nosso objetivo principal foi observar a abordagem das provas matemáticas durante as aulas. Focamos nos discursos, argumentos, ideias, juízos e razões apresentadas pelos professores quando da sua abordagem nas turmas do ensino médio de uma escola pública estadual.

Apoiamo-nos ainda nas gravações de áudio realizadas no acompanhamento das aulas e entrevistas.

As anotações de campo elaboradas durante a observação nos encontros nos auxiliaram nas análises, pois destacamos nelas aspectos importantes, atribuindo-lhes possíveis sentidos com base no referencial teórico delimitado.

\subsection{As entrevistas}

As entrevistas foram utilizadas para esclarecer, enriquecer e aprofundar os dados coletados nos encontros e atividades. Para tanto, utilizamos a gravação em áudio. Minayo (1994, p.15) define a entrevista como:

[...] O procedimento mais usual no trabalho de campo. Através dela, o pesquisador busca obter informes contidos na fala dos atores sociais. Ela não significa uma conversa despretensiosa e neutra, uma vez que se insere como meio de coleta dos fatos relatados pelos atores enquanto sujeito objeto da pesquisa que vivenciam uma determinada realidade que está sendo focalizada. (...) conversa a dois com propósitos bem definidos.

Sendo ela utilizada "[...] para recolher dados descritivos na linguagem do próprio sujeito, permitindo ao investigador desenvolver intuitivamente uma ideia sobre a maneira como os sujeitos interpretam aspectos do mundo". (Bogdan e Biklen,1994, p. 134).

As entrevistas realizadas ocorreram nas dependências da própria escola em horários de intervalos, aulas vagas e ainda de trabalho coletivo existente. Buscamos obter mais dados e esclarecer dúvidas oriundas do acompanhamento das aulas.

\subsection{Caracterização da escola}

Definida nossa proposta de pesquisa que consiste em investigar e responder a questão: “os professores do ensino médio da escola pública privilegiam as provas matemáticas em sala de aula?" - escolhemos uma escola pública, na região de nosso domicílio, que ofertasse o 
ensino médio. Sendo assim, escolhemos uma escola pertencente â rede estadual de ensino, na região leste da grande São Paulo.

A escola funciona em três turnos (manhã, tarde e noite) e oferece o ensino fundamental II no período da tarde e médio, na manhã e noite. Ela possui saneamento básico e razoável infraestrutura. A escola possui aproximadamente 2000 alunos, em sua maioria residente no entorno da escola. A maioria do corpo docente possui licenciatura plena e é concursada.

As aulas na escola escolhida são frequentemente acompanhadas pelos professores coordenadores e alunos de licenciatura, em estágio supervisionado. Assim, fomos recebidos de forma muito natural pelos professores de matemática da escola e a coordenação os informou que acompanharíamos as aulas com o intuito de elaborar um levantamento sobre os conteúdos abordados no ensino médio.

\subsection{Caracterização dos professores acompanhados}

Os quatro professores que participam desta pesquisa são todos concursados na rede estadual, com licenciatura plena e com média de experiência no magistério de 13 anos. Apenas os professores Carlos e Danilo lecionam em mais de uma rede de ensino, municipal e particular, respectivamente.

\begin{tabular}{|l|l|l|l|}
\hline \multicolumn{3}{|c|}{ Caracterização dos professores } \\
\hline Professores & Formação & $\begin{array}{l}\text { Rede de ensino de formação } \\
\text { superior }\end{array}$ & Tempo de magistério \\
\hline Alberto, & $\begin{array}{l}\text { Licenciatura em } \\
\text { Matemática }\end{array}$ & Particular & $\begin{array}{l}6 \text { anos no ensino fundamental e } \\
\text { médio }\end{array}$ \\
\hline Beatriz & $\begin{array}{l}\text { Licenciatura em } \\
\text { Matemática }\end{array}$ & Particular & $\begin{array}{l}20 \text { anos no ensino fundamental e } \\
\text { médio }\end{array}$ \\
\hline Carlos & $\begin{array}{l}\text { Licenciatura em } \\
\text { Matemática }\end{array}$ & Particular & 17 anos no ensino médio \\
\hline Danilo & $\begin{array}{l}\text { Licenciatura em } \\
\text { Matemática }\end{array}$ & Particular & $\begin{array}{l}9 \text { anos no ensino fundamental e } \\
\text { médio }\end{array}$ \\
\hline
\end{tabular}




\section{Capítulo 4}

Neste capítulo apresentamos uma descrição e análise dos acompanhamentos realizados. Acompanhamos quatro professores em suas aulas para turmas do ensino médio, durante os horários normais de aulas de uma escola da rede estadual de São Paulo. Ainda acompanhamos os professores durante suas aulas vagas, intervalos e horários coletivos buscando, em conversas informais, mais dados para subsidiar nossa pesquisa.

\section{Acompanhamento e análise das aulas}

A seguir, elaboramos uma descrição das 46 aulas acompanhadas durante a pesquisa, todas elas ministradas por quatro professores licenciados em matemática do ensino médio de uma escola pública da rede estadual de São Paulo. Professores esses que nos referiremos durante esse trabalho pelos nomes: Alberto, Beatriz, Carlos e Danilo.

As primeiras 28 aulas serviram para identificar os professores que privilegiavam as provas matemáticas em suas aulas e utilizamos as demais 18 aulas para acompanhar as aulas desse professor.

\subsection{As primeiras aulas}

Nas primeiras 28 aulas, acompanhamos 7 aulas de cada um dos quatro professores. Foi suficiente para perceber que apenas um deles, professor Danilo, privilegiava as provas matemáticas durante suas aulas no ensino médio.

\section{Professores Alberto, Beatriz e Carlos.}

Os três professores possuem uma prática pedagógica semelhante, apresentavam as definições e propriedades, elaboravam alguns exemplos numéricos em aula para os alunos perceberem a validade das propriedades, mais exemplos e exercícios de fixação.

Exemplo de abordagem de propriedade logarítmica: $\log _{a} b \cdot c=\log _{a} b+\log _{a} c$.

- Essa propriedade é muito importante, pois deixa os cálculos mais simples. (Professor Carlos). 
O professor chama a atenção da utilidade da propriedade e segue apresentando os exemplos:

$\mathrm{O} \log _{2} 16=x$, usando a definição de logaritmos temos que $\mathrm{x}=4$.

$\mathrm{O} \log _{2} 2=x$ e temos que $\mathrm{x}=1$.

$\mathrm{O} \log _{2} 8=x$ e temos que $\mathrm{x}=3$.

$\log _{2} 16=\log _{2}(2.8)=\log _{2} 2+\log _{2} 8=1+3=4$.

- Acreditem é sempre válida, observe as outras propriedades no livro, elas são todas verdadeiras, podemos também verificar com alguns exemplos (Professor Carlos).

O professor indica a autoridade do livro didático como justificativa para a veracidade da propriedade, apontando para um esquema de prova por convicção externa, e ainda sugere a verificação de alguns casos numéricos que podem eximir dúvidas, o que pode incentivar os alunos a elaborarem provas pragmáticas.

Ainda nas aulas acompanhadas do professor Carlos, percebemos uma preferência por exercícios de vestibulares, principalmente de instituições públicas.

- Vocês precisam se habituar à forma de resolução de problemas, interpretar e saber elaborar a resolução. Precisam conhecer bem e praticar. Essa é uma das formas que vocês terão para alcançarem um futuro melhor, é a oportunidade de entrarem em uma universidade pública de qualidade. (Professor Carlos).

Nas entrevistas, percebemos uma preocupação dos professores Carlos e Beatriz com desempenho dos alunos nas avaliações externas SARESP (Sistema de Avaliação do Rendimento Escolar do Estado de São Paulo) e ENEM (Exame Nacional do Ensino Médio). Para eles é muito importante a escola preparar os alunos para esses testes, tanto para o desempenho positivo da instituição escolar na rede estadual (SARESP), como também para o futuro escolar dos alunos (ENEM) e sua continuidade nos estudos após o ensino médio.

A justificativa indicada pelos professores Carlos e Beatriz, para o modelo seguido em suas aulas, são as cobranças que recebem internamente: pais, direção e coordenação escolar e externamente, pela Secretaria de Educação.

- Os alunos devem saber resolver problemas, saber calcular, identificar, reconhecer, aplicar, conhecer, (...), são as habilidades exigidas nas avaliações externas e é assim 
que devemos trabalhar para alcançar os resultados. A escola e os pais nos cobram a toda hora. (Professora Beatriz).

Percebemos uma visão utilitária da matemática por parte desses professores; para eles, os alunos devem conhecer todos os conteúdos, regras e fórmulas matemáticas previstas nesse nível de ensino, para serem capazes de resolver problemas e melhorarem o desempenho da unidade escolar nas avaliações externas. Foco no conteúdo com ênfase no desempenho.

- Vamos, pessoal, estamos muito atrasados e temos que cumprir os conteúdos previstos, vocês vão terminar sendo prejudicados. E isso não vou permitir. (Professora Beatriz).

Como a professora Beatriz, todos os professores perseguem um cronograma e o seguem com pouco espaço para mudanças. O cumprimento integral dos conteúdos previstos no plano de ensino tem grande importância para todos. Consequentemente, percebemos aulas engessadas, com pouco espaço para a interação dos alunos.

- A maioria dos alunos já possui muitas dificuldades para acompanhar nossas aulas dessa forma, eles já estão acostumados e se sentem bem, muitos conseguem resolver alguns problemas, poucos têm facilidade na disciplina. (Professor Alberto).

O professor Alberto, apesar de utilizar o mesmo modelo dos dois professores anteriores, expõe que o modelo seguido tem a intenção de motivar os alunos com mais dificuldades e ainda manter a ordem na sala de aula. O professor é o que possui a menor experiência no magistério entre os professores acompanhados.

- Os alunos são terríveis (...) Às vezes, precisamos mantê-los ocupados o tempo todo, senão começam a bagunçar e recebemos reclamações. Dizem que não conseguimos tomar conta da sala,..., Acredito que eles deveriam nos ajudar, mas a política é "não nos tragam problemas". (...) Aprendi que devemos sempre manter os alunos ocupados, não os deixo respirar. (Professor Alberto).

Outra preocupação dos professores em sala de aula é a organização escolar e a indisciplina dos alunos, que impacta na organização das aulas e consequentemente na sua prática escolar.

Quando perguntado ao professor Alberto quanto à elaboração de provas matemáticas apresentadas no livro didático dos alunos, ele responde:

- Eles já não conseguem acompanhar o básico, imagina se complicar. Dando o básico, já não consigo a atenção e eles têm dificuldades. Eu apresento a definição e exemplos. Então proponho alguns exercícios, muitos conseguem seguindo esse 
ritmo e se sentem capazes (...) de outra forma eles vão mal, ou pior, eles não se sentem capazes, destruímos a delicada autoestima que possuem. (Professor Alberto).

Assim o professor demonstra não acreditar ser possível a abordagem das provas matemáticas em sala de aula, pois nada traria de benéfico para seus alunos, ao contrário, assume um papel de desestímulo para eles, visto sua complexidade.

Os três professores utilizam modelos em sala de aula no ensino médio, levando em consideração os objetivos que julgam importantes para o desempenho dos alunos em avalições internas e externas, o comportamento dos alunos, ritmo das aulas, a organização escolar e ainda avaliam as provas matemáticas como uma temática de difícil compreensão, algo complicado e desestimulante para seus alunos.

- Com a prática percebemos o que dá certo (...) o caminho a seguir, como conseguir, dar um ritmo às aulas e o que tá dando certo, devemos continuar (Professor Carlos).

As práticas de ensino dos professores parecem levar em consideração as experiências em sala de aula, sendo o modelo adotado nas turmas acompanhadas o melhor obtido, até o momento, e que permite manter as aulas em um determinado ritmo, tempo, comportamento e prender a atenção dos alunos. Não sendo necessariamente o modelo que o professor acredita ser a melhor forma, ou o modelo que tenha assistido enquanto aluno na sua vida escolar.

Assim, o modelo pedagógico percebido no acompanhamento das turmas desses três professores, foi o de apresentar os conteúdos matemáticos planejados para aquela determinada turma, fornecer uma explicação e exemplos, e ainda resolver, propor e ajudar os alunos nos exercícios propostos.

\subsection{Aulas do professor Danilo}

-Temos que oportunizar aos alunos a chance de perceberem e acompanharem algumas justificativas matemáticas, já que, elas fazem parte da matemática. É uma parte essencial dela, é importante, assim como a linguagem e simbologia envolvida. É preciso que eles percebam e se acostumem. E isso só é possível tendo contato com elas na escola. (Professor Danilo)

Entre os professores acompanhados, o único que percebemos abordando as provas matemáticas em suas aulas foi o professor Danilo. Sempre que abordava um conteúdo, ele reservava um tempo à elaboração das provas das propriedades apresentadas no livro didático, 
adotado pela escola ou que seguia em suas aulas, fazendo de forma intencional e planejada, em sua prática pedagógica.

Como o professor leciona nos primeiros e segundos anos do ensino médio e abordou as provas matemáticas em mais de um conteúdo matemático, resolvemos, devido as limitações da nossa pesquisa, focar na descrição das aulas envolvendo o tema trigonometria.

\section{$\underline{\text { Tema das aulas: Soma de arcos }}$}

- Considerem o círculo trigonométrico de raio unitário, conforme a figura a seguir. (Professor Danilo).

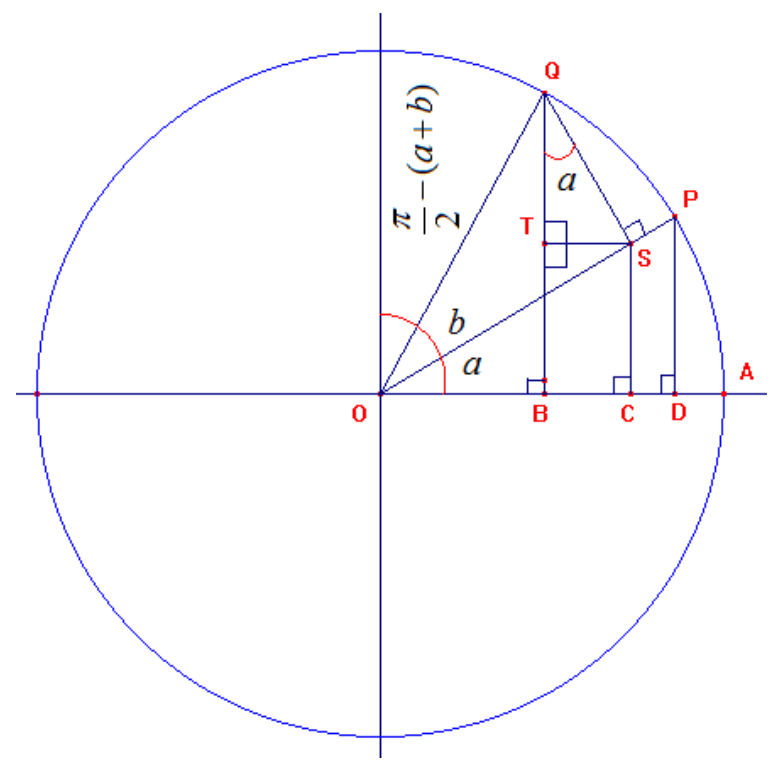

Figura 16 - Soma de arcos Professor Danilo Fonte: Autoria própria

Seja o arco $\widehat{A P}$ com determinação $\boldsymbol{a}$ e o $\operatorname{arco} \widehat{P Q}$ com determinação $\boldsymbol{b}$. O $\operatorname{arco} \widehat{A Q}$ tem determinação $(a+b)$.

O professor Danilo chamou a atenção para os triângulos retângulos presentes na construção. E relacionou, com a participação dos alunos, algumas relações. 


$$
\begin{aligned}
& \cos (a)=\overline{O D} \\
& \operatorname{sen}(a)=\overline{D P} \\
& \cos (b)=\overline{O S} \\
& \operatorname{sen}(b)=\overline{S Q} \\
& \cos (a+b)=\overline{O B} \\
& \operatorname{sen}(a+b)=\overline{B Q}
\end{aligned}
$$

O que permitiu após algumas considerações e explorações de triângulos obterem:

Do $\Delta$ STQ: $\quad \operatorname{sen}(a)=\frac{\overline{T S}}{\overline{Q S}}=\frac{\overline{T S}}{\operatorname{sen}(b)} \Rightarrow \overline{T S}=\operatorname{sen}(a) \operatorname{sen}(b) \mathrm{e}$

$$
\cos (a)=\frac{\overline{Q T}}{\overline{Q S}}=\frac{\overline{Q T}}{\operatorname{sen}(b)} \Rightarrow \overline{Q T}=\cos (a) \operatorname{sen}(b)
$$

Do $\triangle \mathrm{OCS}: \quad \operatorname{sen}(a)=\frac{\overline{C S}}{\overline{O S}}=\frac{\overline{C S}}{\cos (b)} \Rightarrow \overline{C S}=\operatorname{sen}(a) \cos (b)$

$$
\cos (a)=\frac{\overline{O C}}{\overline{O S}}=\frac{\overline{O C}}{\cos (b)} \Rightarrow \overline{O C}=\cos (a) \cos (b)
$$

E finalizaram:

$$
\begin{aligned}
& \operatorname{sen}(a+b)=\overline{B Q}=\overline{Q T}+\overline{T B}=\overline{C S}=\cos (a) \operatorname{sen}(b)+\cos (b) \operatorname{sen}(a) \\
& \cos (a+b)=\overline{O B}=\overline{O C}-\overline{C B}=\overline{T S}=\cos (a) \cos (b)-\operatorname{sen}(a) \operatorname{sen}(b)
\end{aligned}
$$

Quando chamados a participarem das aulas, os alunos demonstraram uma clareza sobre o desenvolvimento das ideias apresentadas pelo professor, sempre apoiados na figura 16.

Nessas aulas, a turma se envolveu ativamente, tendo os alunos espaços para argumentar e participar.

Mesmo privilegiando as provas matemáticas em sua prática pedagógica o professor Danilo, exceção feita à aula anterior acompanhada, não abre espaço nas aulas para a participação dos alunos argumentarem, questionarem ou discutirem sobre o que vai ser abordado, cabendo aos alunos apenas o papel de ouvintes. 


\section{Tema da aula: Função Par e Ímpar.}

O professor Danilo iniciou uma das aulas recordando aos alunos as definições de função par e ímpar, dado no ano anterior no estudo de funções, usando as funções quadrática, $\mathrm{f}(\mathrm{x})=\mathrm{x}^{2}$ e cúbica, $\mathrm{f}(\mathrm{x})=\mathrm{x}^{3}$, apoiado aos respectivos gráficos das duas funções e concluiu, com base na figura 17, que a função seno é ímpar e a cosseno par.

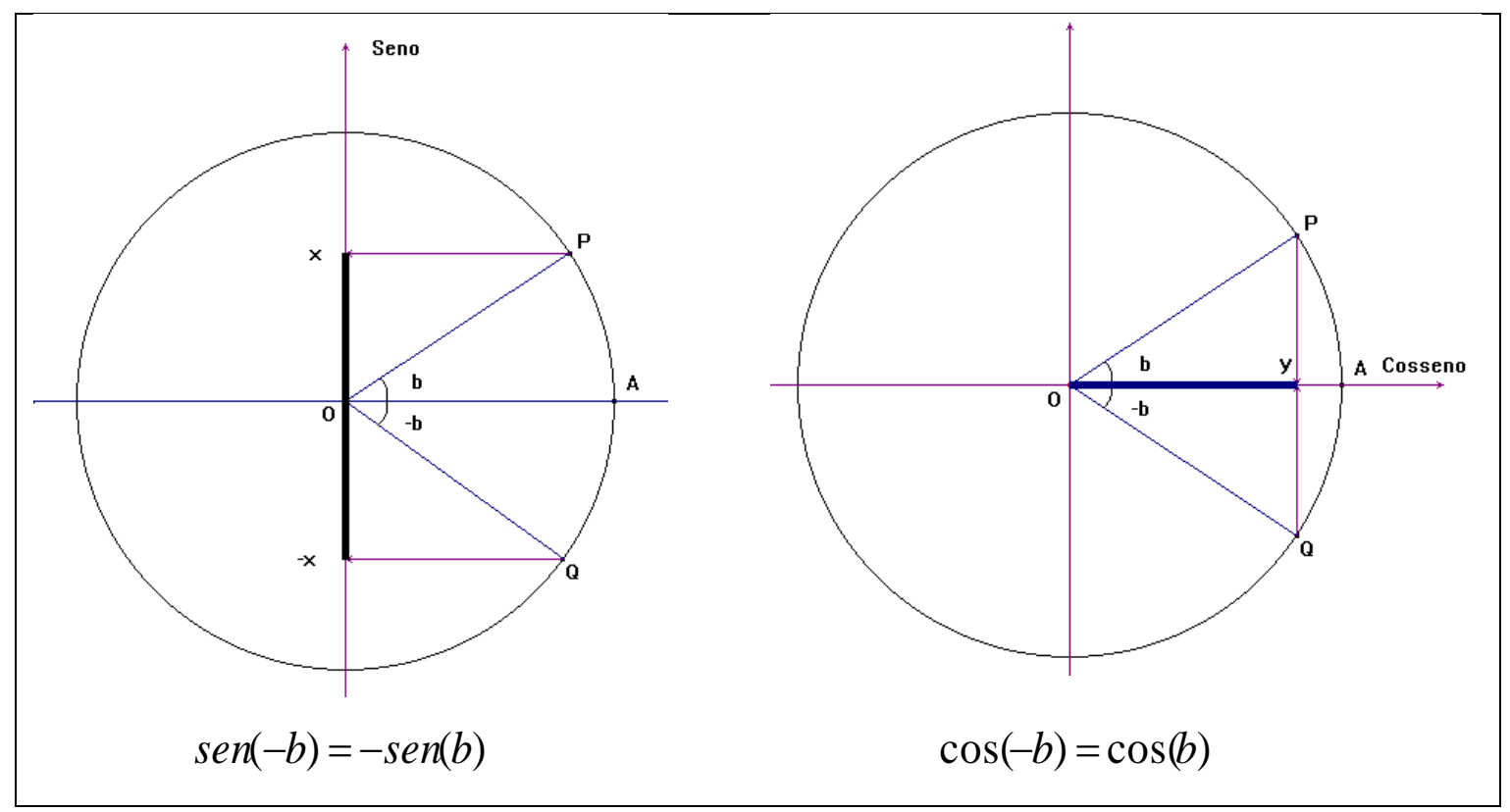

Figura 17 - Par e Impar

Fonte: Autoria própria

Tema das aulas: Diferença de arcos.

Em seguida, elaborou as identidades para diferença de arcos, como segue:

$\operatorname{sen}(a-b)=\operatorname{sen}[a+(-b)]=\operatorname{sen}(a) \cos (-b)+\operatorname{sen}(-b) \cos (a)$

Mas como, $\left\{\begin{array}{c}\operatorname{sen}(-b)=-\operatorname{sen}(b) \\ \cos (-b)=\cos (b)\end{array} \quad\right.$ continuou:

$$
\operatorname{sen}(a-b)=\operatorname{sen}(a) \cos (b)-\operatorname{sen}(b) \cos (a)
$$

O mesmo ocorreu com cosseno.

$$
\cos (a-b)=\cos (a) \cos (b)+\operatorname{sen}(a) \operatorname{sen}(b)
$$


Ainda deduziu a soma e diferença de arcos da tangente.

- Usando as identidades anteriores, podemos provar algumas identidades que serão úteis (Professor Danilo).

$$
\begin{aligned}
& \cos \left(\frac{\pi}{2}-x\right)=\cos \frac{\pi}{2} \cdot \cos x+\operatorname{sen} \frac{\pi}{2} \cdot \operatorname{sen} x=0 \cdot \cos x+1 \cdot \operatorname{sen} x=\operatorname{sen} x \\
& \operatorname{sen}\left(\frac{\pi}{2}-x\right)=\cos \left[\frac{\pi}{2}-\left(\frac{\pi}{2}-x\right)\right]=\cos \left[\frac{\pi}{2}-\frac{\pi}{2}+x\right]=\cos x \\
& \cos (\pi-x)=\cos \pi \cdot \cos x+\operatorname{sen} \pi \cdot \operatorname{sen} x=-1 \cdot \cos x+0 \cdot \operatorname{sen} x=-\cos x \\
& \cos (-x)=\cos (0-x)=\cos 0 \cdot \cos x+\operatorname{sen} 0 \cdot \operatorname{sen} x=1 \cdot \cos x+0 \cdot \operatorname{sen} x=\cos x
\end{aligned}
$$

Notamos, durante a abordagem dos exercícios em sala, a dificuldade dos alunos na manipulação algébrica de algumas expressões, dificuldades simples como regra de sinais e frações.

$$
\begin{aligned}
& \operatorname{sen}(-x)=\cos \left[\frac{\pi}{2}-(-x)\right]=\cos \left[\frac{\pi}{2}+x\right]=-\cos \left[\pi-\left(\frac{\pi}{2}+x\right)\right]=-\cos \left[\pi-\frac{\pi}{2}-x\right]= \\
& =-\cos \left[\frac{\pi}{2}-x\right]=-\operatorname{sen} x \\
& \operatorname{sen}(-x)=\cos (0-x)=\cos 0 \cdot \cos x+\operatorname{sen} 0 \cdot \operatorname{sen} x=1 \cdot \cos x+0 \cdot \operatorname{sen} x=\cos x \\
& \operatorname{sen}\left(\frac{\pi}{2}-x\right)=\cos \left[\frac{\pi}{2}-\left(\frac{\pi}{2}-x\right)\right]=\cos \left[\frac{\pi}{2}-\frac{\pi}{2}+x\right]=\cos x
\end{aligned}
$$

Com o auxílio dessas identidades ainda foi demonstrada:

$$
\cos (a+b)=\cos (a-(-b))=\cos a \cdot \cos (-b)+\operatorname{sen} a \cdot \operatorname{sen}(-b)=\cos a \cdot \cos b-\operatorname{sen} a \operatorname{sen} b
$$

$$
\therefore \cos (a+b)=\cos a \cdot \cos b-\operatorname{sen} a \cdot \operatorname{sen} b(\text { II) }
$$

$\operatorname{sen}(a-b)=\cos \left[\frac{\pi}{2}-(a-b)\right]=\cos \left[\left(\frac{\pi}{2}-a\right)+b\right]=\cos \left(\frac{\pi}{2}-a\right) \cdot \cos b-\operatorname{sen}\left(\frac{\pi}{2}-a\right) \cdot \operatorname{sen} b=$ sen $a \cos b-\cos a \operatorname{sen} b=\operatorname{sen} a \cos b-\operatorname{sen} b \cdot \cos a$

$\operatorname{sen} a \cos b-\cos a \operatorname{sen} b=\operatorname{sen} a \cos b-\operatorname{sen} b \cdot \cos a$ 
$\operatorname{sen}(a+b)=\operatorname{sen}(a-(-b))=\operatorname{sen} a \cos (-b)-\operatorname{sen}(-b) \cos a=\operatorname{sen} a \cos b+\operatorname{sen} b \cdot \cos a$

$$
\therefore \operatorname{sen}(a+b)=\operatorname{sen} a \cos b+\operatorname{sen} b \cdot \cos a(\mathrm{IV})
$$

O professor abordou as provas em detalhes em algumas turmas; em outras, sua prática pedagógica se assemelha a dos outros professores.

Tema das aulas: Arco duplo.

Nesta aula, o professor iniciou recordando as relações anteriores e as manipulando, como segue:

$$
\operatorname{sen}(a+b)=\operatorname{sen}(a) \cos (b)+\operatorname{sen}(b) \cos (a)
$$

Fazendo a=b, na relação anterior:

$$
\operatorname{sen}(a+a)=\operatorname{sen}(a) \cos (a)+\operatorname{sen}(a) \cos (a)
$$

$$
\operatorname{sen}(2 a)=2 \operatorname{sen}(a) \cos (a)
$$

Da mesma forma usando o mesmo raciocínio para o cosseno.

$$
\cos (a+a)=\cos a \cdot \cos a-\text { senasen } a \Rightarrow \cos (2 a)=\cos ^{2} a-\operatorname{sen}^{2} a
$$

O professor chamou a atenção para as variações do arco duplo do cosseno que pode assumir, devido à identidade $\cos ^{2} a+\operatorname{sen}^{2} a=1$, que são:

$$
\begin{aligned}
& \cos (2 a)=1-\operatorname{sen}^{2} a-\operatorname{sen}^{2} a=1-2 \operatorname{sen}^{2} a \\
& \cos (2 a)=\cos ^{2} a-\left(1-\cos ^{2} a\right)=1+2 \cos ^{2} a
\end{aligned}
$$

Tendo encerrado demonstrando a relação da tangente da adição:

$$
\operatorname{tg}(a+b)=\frac{\operatorname{tg} a+\operatorname{tg} b}{1-\operatorname{tg} a . \operatorname{tg} b} \Rightarrow \operatorname{tg}(2 a)=\frac{2 \operatorname{tg} a}{1-\operatorname{tg}^{2} a}
$$

O professor apenas expõe todo o processo e os alunos acompanham. 


\section{$\underline{\text { Tema das aulas: Lei dos Senos }}$}

Sendo duas de suas alturas: $\mathrm{AH}_{1}$ e $\mathrm{AH}_{2}$.

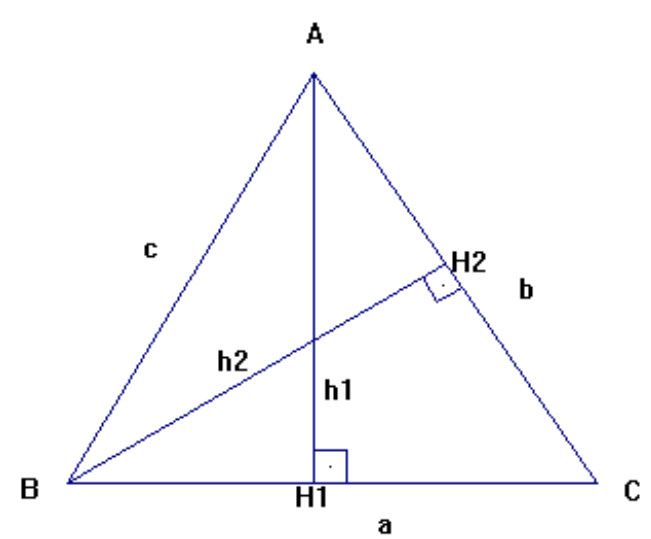

Observe que triângulo ACH1 é retângulo em H1. Logo:

$$
\operatorname{sen} \hat{C}=\frac{h 1}{b} \Rightarrow h 1=b \cdot \operatorname{sen} \hat{C}
$$

Ainda que triângulo ABH1 é retângulo em H1. Logo:

$$
\operatorname{sen} \hat{B}=\frac{h 1}{c} \Rightarrow h 1=c . \operatorname{sen} \hat{B}
$$

Comparando as igualdades, temos:

$$
b \cdot \operatorname{sen} \hat{C}=c \cdot \operatorname{sen} \hat{B} \Rightarrow \frac{b}{\operatorname{sen} \hat{B}}=\frac{c}{\operatorname{sen} \hat{C}}
$$

Figura 18 - Lei dos senos Professor Danilo

Fonte: Autoria própria

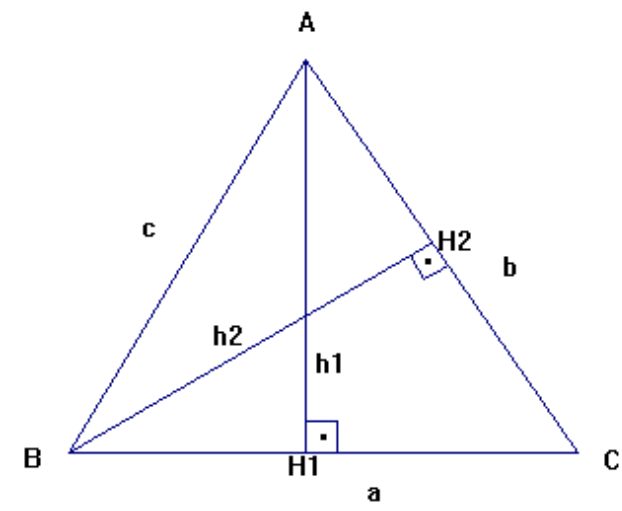

Figura 19 - Lei dos senos Professor Danilo 2

Fonte: Autoria própria

No triângulo BCH2 é retângulo em H2. Logo:

$\operatorname{sen} \hat{C}=\frac{h 2}{a} \Rightarrow h 2=a \cdot \operatorname{sen} \hat{C}$

No triângulo ABH2 retângulo em H2. Logo:

$\operatorname{sen} \hat{A}=\frac{h 2}{c} \Rightarrow h 2=c \cdot \operatorname{sen} \hat{A}$

Comparando as igualdades, temos:

$$
\operatorname{arsen} \hat{C}=c \cdot \operatorname{sen} \hat{A} \Rightarrow \frac{a}{\operatorname{sen} \hat{A}}=\frac{c}{\operatorname{sen} \hat{C}}
$$

$$
\frac{a}{\operatorname{sen} \hat{A}}=\frac{b}{\operatorname{sen} \hat{B}}=\frac{c}{\operatorname{sen} \hat{C}}
$$




\section{$\underline{\text { Tema das aulas: Teorema dos cossenos }}$}

Para qualquer triângulo $\mathrm{ABC}$, o quadrado da medida de um lado é igual à soma dos quadrados das medidas dos outros dois lados menos o dobro do produto dessas medidas pelo cosseno do ângulo compreendido por eles.

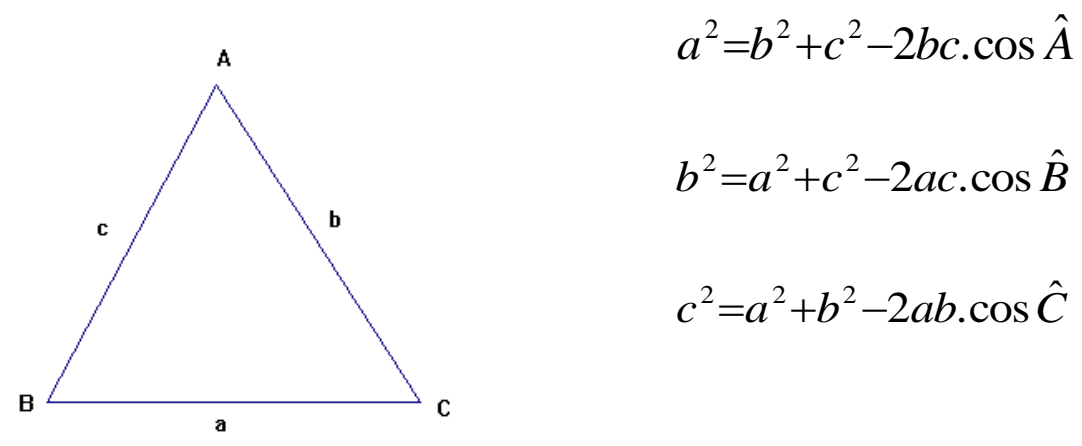

Figura 20 - Lei dos cossenos Prof Danilo

Fonte: Autoria própria

- Vamos demonstrar a primeira relação, considerando o ângulo A agudo, as demonstrações das outras relações achamos de modo análogo. (Professor Danilo).

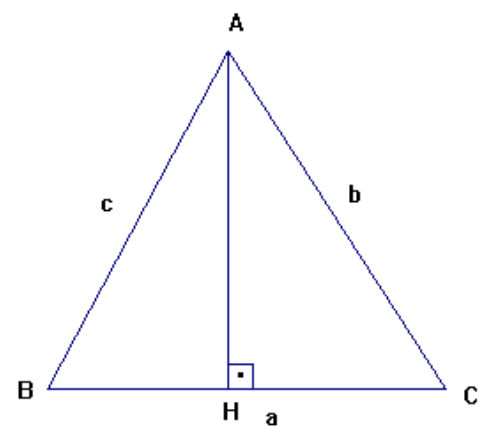

Figura 21 - Lei dos cossenos Prof Danilo 2

Fonte: Autoria própria

Traçando a altura $\mathrm{BH}$, teremos os triângulos retângulos $\mathrm{ABH}$ e $\mathrm{CBH}$. No triângulo $\mathrm{ABH}$, temos: 


$$
\left\{\begin{array}{c}
\cos \hat{A}=\frac{A H}{c} \Rightarrow A H=c \cdot \operatorname{sen} \hat{A} \\
c^{2}=h^{2}+A H^{2} \Rightarrow h^{2}=c^{2}-A H^{2} \Rightarrow h^{2}=c^{2}-(c \cdot \cos \hat{A})^{2} \Rightarrow \\
\Rightarrow h^{2}=c^{2}-c^{2} \cdot \cos ^{2} \hat{A}(I)
\end{array}\right.
$$

No triângulo $\mathrm{CBH}$, temos:

$$
\left\{\begin{array}{c}
a^{2}=h^{2}+C H^{2} \Rightarrow a^{2}=h^{2}-(b-A H)^{2} \Rightarrow \\
\quad \Rightarrow h^{2}=a^{2}-(b-c \cdot \cos \hat{A})^{2} \Rightarrow \\
\Rightarrow h^{2}=a^{2}-b^{2}+2 b c \cdot \cos \hat{A}-2 b c \cdot \cos \hat{A}(I I)
\end{array}\right.
$$

De (I) e (II) temos:

$$
a^{2}-b^{2}+2 b c \cdot \cos \hat{A}-2 b c \cdot \cos \hat{A}=c^{2}-c^{2} \cdot \cos ^{2} \hat{A} \Rightarrow
$$

$$
\Rightarrow a^{2}=b^{2}+c^{2}-2 b c \cdot \cos \hat{A}
$$

- Os alunos devem ter a oportunidade de ter contato com as provas matemáticas, os professores precisam trabalhar visando-as com seus alunos em sala de aula. (Professor Danilo).

Nessas aulas, apesar do professor Danilo abordar as provas matemáticas, pouco espaço deixa para a participação dos alunos, o que não é o ideal, pois acreditamos que o ensino e aprendizagem das provas matemáticas seja um processo, e como tal, deve ocorrer com a participação ativa dos envolvidos, eles devem ter espaços garantidos para argumentar, levantar hipóteses, elaborar conjecturas e avançar nos níveis de provas elaboradas.

- Gosto de elaborar as provas matemáticas das propriedades, elas estão lá. Os alunos interessados também participam (...) Eu gosto de abordar em sala de aula. É bom sempre nos atualizarmos. (Professor Danilo).

Apesar de atribuir importância às provas matemáticas o professor indicar um interesse pessoal na sua elaboração, tendo uma visão focada no conteúdo com ênfase no entendimento conceitual. Aborda as provas na maioria das turmas, mas com pouco espaço para a participação ativa dos alunos. Em algumas turmas - "as mais interessadas" - 
permite aos alunos, às vezes, participar argumentando, questionando, levantando hipóteses ou compartilhando ideias.

- Algumas salas da para trabalhar outras não. Alguns alunos só querem saber se cai na prova e qual é a fórmula que precisa usar. Mas outros alunos acompanham e dizem: "professor agora entendi". "agora ficou claro por que vale sempre". E isso é muito legal ouvir. ( Professor Danilo)

Deixando claro que a abordagem das provas matemáticas no ensino médio, para esse professor, está condicionada ao interesse e nível escolar das turmas.

Acreditamos que o ensino e aprendizagem das provas matemáticas desempenham funções distintas, sempre mobilizando habilidades próprias do pensamento racional. E que um processo bem planejado para todos os alunos permite avançar nos níveis de argumentação e provas durante a educação básica. No entanto, percebemos que a abordagem está mais associada a um gosto pessoal do professor, do que em um trabalho sistemático escolar e em apenas algumas turmas com espaço para a participação dos alunos.

Mesmo sendo a abordagem do professor Danilo predominantemente expositiva, ele pelo menos privilegia as provas matemáticas em suas aulas, possibilitando aos alunos acompanhar as justificativas das propriedades apresentadas nos livros didáticos. Sua abordagem é diferente da utilizada pelos outros professores acompanhados, que apenas apresentam as propriedades, elaboram exemplos a partir da máxima "façam de acordo com o visto anteriormente". 


\section{Considerações finais}

O objetivo principal deste estudo foi buscar respostas para as perguntas: "os professores do ensino médio privilegiam ou não as provas matemáticas em suas aulas? De que forma? Que tipologias de provas buscam desenvolver em sala de aulas ou elaboram?”

Sabendo existir uma distância entre o discurso e a ação efetivamente realizada, resolvemos elaborar um estudo de caso, acompanhando quatro professores de matemática do ensino médio em sala de aula.

Mesmo as pesquisas encontradas em educação matemática nos últimos anos indicarem sua importância na educação básica, bem como na formação de professores, nas aulas acompanhadas, percebemos que os professores no ensino médio, em geral, não privilegiam as provas matemáticas em suas aulas nesse nível de ensino, mesmo elas permeando os objetos matemáticos.

Para a maioria dos professores acompanhados nesse estudo, percebemos uma visão utilitária da matemática. Para eles, os alunos devem conhecer as regras, propriedades, saber calcular e resolver os problemas envolvendo os conteúdos ministrados nesse nível de ensino, para serem capazes de resolver os problemas abordados nas avaliações internas e externas das quais a escola participa e consequentemente melhorarem o desempenho da unidade escolar. Portanto, com o foco no conteúdo com ênfase no desempenho, de acordo com Thompson (1992).

Como indicam as pesquisas, as concepções dos professores podem influenciar na sua prática pedagógica, mas percebemos ainda uma grande atenção com os seguintes fatores: interesse das turmas, organização da sala, indisciplina e comportamentos dos alunos e abordagem dos conteúdos previstos, além do desempenho dos alunos nas avaliações.

O modelo pedagógico, percebido no acompanhamento das turmas da maioria dos professores, foi o de apresentação dos conteúdos matemáticos previstos para aquela determinada turma, elaboração de uma explicação e exemplos, e o auxílio aos alunos para resolução de exercícios propostos.

Presenciamos a referência à autoridade do livro didático como justificativa para a veracidade das propriedades, apontando para um esquema de prova por convicção externa, conforme Harel e Sowder (2007), e ainda a sugestão da verificação de alguns casos numéricos nas propriedades, apresentada como meio de dirimir dúvidas da validade, o que pode servir de 
referência aos alunos na elaboração de suas justificativas, provas pragmáticas, (Balacheff, 1987).

Tivemos a oportunidade de perceber a abordagem das provas matemáticas durante as aulas acompanhadas, de forma planejada e intencional, permeando os objetos matemáticos, por exemplo: logaritmos e trigonometria. Na exploração das propriedades trigonométricas, foi onde a abordagem das provas matemáticas mais ocorreram. Provas intelectuais, para Balacheff (1987).

Mesmo constatando um dos professores, Danilo, privilegiando as provas matemáticas em sua prática pedagógica, pouco espaço possuem os alunos para a participação e efetivamente argumentarem, questionarem ou discutirem sobre o que foi abordado. Cabendo a eles, em grande parte, apenas o papel de ouvintes.

Apesar de atribuir importância às provas matemáticas no ensino médio, o professor Danilo indica um interesse pessoal na sua elaboração, tendo uma visão focada no conteúdo com ênfase no entendimento conceitual, conforme Thompson (1992). Aborda as provas na maioria das turmas, mas pouco espaço deixa para a participação ativa dos alunos, exceção feita a algumas turmas - "as mais interessadas e capazes".

O que encontramos não é o ideal, pois acreditamos que o ensino e aprendizagem das provas matemáticas seja um processo, e como tal, deve ocorrer num ambiente participativo. Os alunos devem ter garantidos espaços para argumentar, levantar hipóteses, elaborar conjecturas e avançarem nos níveis de provas elaboradas.

Acreditamos que o ensino e aprendizagem das provas matemáticas desempenham funções distintas, sempre mobilizando habilidades próprias do pensamento racional, e que um processo bem planejado para todos os alunos permite avançar nos níveis de argumentação e de provas durante a educação básica. No entanto, percebemos que a abordagem está mais associada a um interesse pessoal do professor, do que em um trabalho sistemático escolar e em apenas poucas turmas com espaço para a participação efetiva dos alunos. 


\section{Referências Bibliográficas}

ALMOULOUD, S. A.; FUSCO, C. A. Discutindo algumas dificuldades de professores dos ensinos Fundamental e Médio a respeito do conceito de demonstração. In: Anais do III SIPEM - Simpósio Internacional de Pesquisa em Educação Matemática, Água de Lindóia, SP, 2006.

ARSAC, G. L'origine de la dèmonstration: essai d'Épistémologie didactique. Recherches en Didactique des Mathémtiques, V. 8, n. 3, p. 267-312, 1987.

BALACHEFF, N. Es la argumentación un obstáculo? 1999. Disponível:

(http://athena.mat.ufrgs.br/ portosil/result2.html). Acesso em 29 de março de 2011.

. Processus de preuve et situations de validation. Educational Studies in Mathematics, vol.18, n.2, p.147-176,1987.

Procesos de prueba en los alumnos de Matemáticas. Uma empresa docente, Universidad de los Andes. Bogotá, Colombia, 2000.

BOGDAN, R. \& BILKEN, S. Investigação qualitativa em educação. Porto: Porto Editora, 1994.

BRASIL. Ministério da Educação e do Desporto/Secretaria de Educação Média e Tecnológica. PCN+ - Ensino Médio. Brasília: MEC, 2002.

De VILLIERS, M. Papel e funções da demonstração no trabalho com o Sketchpad. Revista Educação e Matemática, Junho, Nº. 63, p. 31-36, 2001.

.The role and function of proof in Mathematics. Pythagoras, n. 24, p. 17-24, 1990.

$30,1993$.

. El papel y la función de la demostración en matemáticas. Em Épsilon, 26, p. 15-

EVES, H. "Introdução à História da Matemática"- trad de Hygino H. Domingues, Editora da UNICAMP, 1995.

HANNA, G. Proof, Explanation and Exploration: an overview. Educational Studies in Mathematics (ESM) 44, Kluwer Academic Publishers: Dordrecht, Holanda, 2001.

HAREL, G. e SOWDER, L. Towards comprehensive perspectives on the learning and teaching of proof, en F.K. Lester (Ed.), Second Handbook of Research on Mathematics Teaching and Learning (p. 805-842). Charlotte, NC: NCTM and IAP, 2007.

LEANDRO, E. J. Um Panorama de Argumentação de alunos da Educação Básica: O caso do fatorial. Dissertação de Mestrado, 2006.

LÜDKE, M., ANDRÉ, M. Pesquisa em educação; abordagens qualitativas. São Paulo: EPU. $10^{\mathrm{a}}$ Ed. 2007. 
PAIVA, Manoel. Matemática, Volume único, Ed; São Paulo: Moderna, 2003.

REID, D. A., \& KNIPPING, C. Proof in Mathematics Education: Research, Learning and Teaching. Netherlands: Sense Publishers, 2010.

THOMPSON, A. G. Teachers' beliefs and conceptions: A synthesis of the research.

Handbook of research in mathematics teaching and learning. D. A. Grows (Ed.), pp. 127- 146. New York: Macmillan, 1992.

YIN, R. K. Estudo de Caso: Planejamento e Métodos. Porto alegre: Ed. Bookman Cia, 2010. 